\title{
Las estadisticas de criminalidad sexual en España: una propuesta de caracterización
}

Statistics about Sexual Violence. A first approache

\author{
Esmeralda Ballesteros Doncel \\ Universidad Complutense de Madrid \\ e.ballesteros@cps.ucm.es (ESPAÑA)
}

Francisca Blanco Moreno

Universidad Complutense de Madrid fblancom@ucm.es (ESPAÑA)

Recibido: 11.11 .2019
Aceptado: 11.01 .2021

\section{RESUMEN}

La violencia sexual contra mujeres y niñas es una de las formas más brutales de violencia de género $\mathrm{y}$, al mismo tiempo, un delito largamente silenciado. La disponibilidad de estadísticas periódicas, rigurosas y confiables es un requisito para monitorizar cualquier fenómeno de interés público y, en el caso de la violencia sexual, un requerimiento ineludible para diseñar políticas e intervenciones orientadas a su prevención, intervención y reparación. Este artículo quiere ser una contribución por las víctimas de cualquier forma de violencia sexual y, en particular, una reflexión política de denuncia ante la injustificada falta de calidad de fuentes cuantitativas para el estudio de este suceso en España. En la primera parte, identificamos los organismos responsables de producir y difundir estadísticas de criminalidad sexual, proponiéndose una primera evaluación de las principales fuentes disponibles que implicaría problematizar sobre el sub-registro estadístico de esta tipología penal y examinar las deficiencias técnicas que presentan los datos publicados. En la segunda parte, presentamos una compilación de las series sobre delincuencia sexual extraídas de los distintos Anuarios Estadísticos publicados por el Ministerio del Interior desde 1987, advirtiendo su escasa capacidad para un estudio cuantitativo riguroso de las violencias sexuales. 


\title{
PALABRAS CLAVE
}

Violencia sexual, Agresión sexual, Violación, Delitos contra la libertad sexual, Estadísticas de criminalidad, Encuestas de Victimización.

\begin{abstract}
Sexual violence against women and girls is one of the most brutal forms of gender violence and, at the same time, a long-silenced crime. The availability of periodic, rigorous and reliable statistics is a requirement to monitor any phenomenon of public interest and, in the case of sexual violence, an unavoidable requirement to design policies and interventions aimed at prevention, eradication, intervention and reparation. This article wants to be a contribution to the struggle of women victims of any form of sexual violence and, in particular, a political reflection of denunciation against the unjustified shortage of quantitative sources and the inexplicable low quality of the data for the study of this event in Spain. In the first part, we identify the agencies responsible for producing and disseminating sexual crime statistics, making a succinct evaluation of the main sources available. In the second part, we present a compilation of the series on sexual delinquency extracted from the different Statistical Yearbooks published by the Ministry of the Interior since 1987, noting its low capacity for a rigorous quantitative study of sexual violence.
\end{abstract}

\section{KEY WORDS}

Sexual violence, Sexual assault, Rape, Sexual violence offences, Crime statistics, Violent sexual crime recorded, Crime Victimization Surveys.

\section{INTRODUCCIÓN}

La violencia sexual contra mujeres y niñas es una de las formas más brutales de violencia de género y, al mismo tiempo, un delito largamente silenciado (Brownmiller 1975: 165; Von Hofer 2000: 85; Marín 2016: 17). Sin embargo, entre los años 2017 y 2018 distintas mujeres han alcanzado un poder de visibilidad pública elevando su voz para señalar a la criminalidad sexual como un problema estructural y universal, para el que se reivindica de manera radical una 'tolerancia cero'. Los movimientos Times Up y Me Too en Estados Unidos, han contribuido a iniciar procesos de sensibilización contra la inercia secular de invisibilización e impunidad en los ataques sexuales. En España, el caso 'San Fermín 2016', también suscitó una intensa movilización, similar al revulsivo que el asesinato de Ana Orantes generó en la concienciación de la violencia de género (Osborne 2008: 100). La discutida sentencia de la Audiencia Provincial 
de Navarra (SAP NA 86/2018) ha provocado, no sólo múltiples concentraciones feministas y ciudadanas, sino también sendos comunicados de asociaciones de profesionales socio-sanitarios y de juezas, sin olvidar el fenómeno digital iniciado por la periodista Cristina Fallarás, invitando a comunicar en Twitter las experiencias de violencia sexual mediante el hashtag \#cuéntalo y que, en tan sólo 10 días, generaron tres millones de tuits y más de 150.000 testimonios de agresión sexual, narrados directamente por sus víctimas ${ }^{1}$. Todas estas resonancias, diversas y multitudinarias, evidencian un antes y un después en la conciencia social del problema, sin olvidar su posible ascendiente en la recalificación judicial de la violación en grupo de San Fermín (STS 2200/2019).

En este artículo se expone una sucinta caracterización de los recursos disponibles para monitorizar la violencia sexual en nuestro país desde una perspectiva cuantitativa, teniendo en cuenta que la disponibilidad de estadísticas periódicas, rigurosas y confiables es un requisito imprescindible para estudiar cualquier fenómeno de interés público (Ley 12/1989 e INE 2014: 2-3) y, en el caso de la violencia sexual, un requerimiento ineludible para diseñar políticas e intervenciones orientadas a su prevención, intervención y reparación. En España, los delitos contra la libertad sexual superan las 15.000 denuncias-año y, sin embargo, los medios de comunicación suelen informar como si estos hechos fueran 'sucesos excepcionales', realizados como un 'extravío' individual de sujetos disfuncionales (Solnit 2016: 25-39), cuando en realidad son prácticas cotidianas, perpetradas fundamentalmente por varones de toda índole, perfectamente integrados en el 'orden' social.

Esta reflexión quiere ser también una contribución a la lucha de las mujeres víctimas de cualquier forma de violencia sexual y, en particular, una reflexión política de denuncia ante la injustificada escasez de fuentes cuantitativas y la inexplicable baja calidad de los datos disponibles para el estudio de este suceso en España. En la primera parte, identificamos los organismos responsables de producir y difundir estadísticas de criminalidad sexual, realizándose una primera evaluación de las principales fuentes disponibles que implica problematizar sobre el subregistro estadístico de esta tipología penal y examinar las deficiencias técnicas que presentan los datos publicados ${ }^{2}$. En la segunda parte, presentamos una monitorización descriptiva de la magnitud y evolución de la criminalidad sexual registrada por los Anuarios Estadísticos del Ministerio del Interior, enfatizando su escasa capacidad para el estudio de las violencias sexuales.

${ }^{1}$ El ingente volumen de información recabado mediante el hashtag \#cuéntalo ha sido parcialmente analizado por el experto en Big Data Fernando Cucchietti, vinculado al Centro Nacional de Supercomputación (BSN), un proyecto al que ha contribuido con "horas extras y compromiso personal" para recoger, limpiar, clasificar y analizar los tres millones de tuits que se publicaron en las dos primeras semanas (El País, 13/XII/2018: «Los 14 días en los que 150.000 mujeres no se callaron»).

2 En el proceso de envío y evaluación de este artículo se publicó un trabajo de evaluación de las estadísticas policiales que referenciamos a las personas interesadas en este tema (Cazorla, 2019). 


\section{FUENTES PARA EL ESTUDIO CUANTITATIVO DE LA VIOLENCIA SEXUAL}

Las manifestaciones de la delincuencia sexual revisten acciones muy diversas que van, por ejemplo, desde el acoso mediante el piropo callejero hasta la violación cruenta, por lo cual deberíamos empezar a hablar de 'violencias' en plural y, así, incorporar los matices inherentes en estos procesos de intimidaciónagresión y sus consecuencias en la vida de las víctimas. La conceptualización de este fenómeno sigue siendo un desafío para la investigación social, en tanto que las estadísticas oficiales en nuestro país consideran como infracción sexual el ataque físico, desatendiendo un buen número de comportamientos reprobables que banalizan y naturalizan acciones de humillación de carácter sexual, que son la base de la 'cultura de la violación' (Burt 1980; Smith 2004; Repullo 2017). Las violencias sexuales son complejas de investigar y no existe una única fuente de datos que proporcione una monitorización completa del suceso, por lo que es necesario contemplar varios tipos de fuentes documentales: a) Estadísticas por registro: estadísticas de criminalidad sexual, estadísticas judiciales y estadísticas penitenciarias b) Investigación Social por Encuesta y c) 'Otras fuentes' para el estudio de la violencia sexual difundidas desde activismos feministas.

\subsection{Estadísticas por registro}

El estudio de la violencia sexual mediante la consulta de estadísticas oficiales por registro debe tener en cuenta dos organismos: Ministerio del Interior y Ministerio de Justicia y, tres fuentes principales de información: 1) Estadísticas de criminalidad, que informan sobre el delito registrado ante los cuerpos de seguridad; 2) Estadísticas judiciales elaboradas por el Consejo General del Poder Judicial y la Fiscalía General del Estado que describen los procedimientos admitidos para ser juzgados y 3) Estadísticas penitenciarias que refieren las características de las personas sancionadas con penas de privación de libertad.

En esta sección evaluaremos de forma exclusiva las estadísticas de criminalidad o estadísticas del delito denunciado, por considerar que monitorizan con mayor alcance las infracciones registradas contra la libertad sexual (Tardón 2017: 246-248 y AI 2018: 18-20).

\subsubsection{Estadísticas de criminalidad o estadísticas sobre el delito denunciado}

En este apartado referenciaremos las estadísticas oficiales producidas por registro y evaluaremos su calidad siguiendo los principios enunciados en los artículos 20-22 de la Ley 12/1989 de la Función Estadística Pública, es decir, los criterios esenciales que deben regir la política de difusión de la información 
estadística: 'Disponibilidad y Accesibilidad', 'Claridad conceptual' y 'Variables de estudio' (INE 2014: 2-3).

El término 'disponibilidad' hace referencia a la posibilidad de consulta pública de datos. La producción de estadísticas oficiales sobre delincuencia en España se realiza mediante la sistematización de las denuncias realizadas ante los cuerpos de seguridad, función que es competencia del Ministerio del Interior (en adelante MIR), siendo el Anuario Estadístico la principal fuente de difusión especializada ${ }^{3}$. La consulta de estas estadísticas se ofrece libremente a la ciudadanía desde al año $1989^{4}$, siendo su calidad y ámbito territorial variable hasta la creación, en el año 2012, del Sistema Estadístico de Criminalidad (SEC), en el que se centralizaron todos los datos procedentes de los distintos cuerpos de seguridad (Policía Nacional y Guardia Civil) y policías autonómicas (RD 400/2012 y Anuario MIR, 2012: 146) ${ }^{6}$, atendiendo al acuerdo del Pleno del Congreso de los Diputados de septiembre de 2011 (Serrano 2011: 454).

Distintos especialistas en análisis de la delincuencia han caracterizado la calidad del banco de datos proporcionado por los Anuarios MIR como insuficiente (Osborne 2008; Aebi y Linde 2010: 3; Serrano 2011: 430; Blay 2013 y Cazorla, 2019). La principal deficiencia señalada ha sido la tardía centralización de la estadística nacional, pues durante más de dos décadas (1989 - 2011) el Anuario sólo publicaba las cifras del delito registrado, en lo que se denominaba territorio MIR, es decir, en los ámbitos geográficos donde tenían competencias la Policía Nacional y la Guardia Civil, quedando excluidas de dicha estadística los datos relativos a Cataluña, País Vasco y Navarra, con competencias transferidas en materia de seguridad ${ }^{7}$. De este modo, cualquier investigación empírica que quisiera ofrecer una visión completa del territorio español, entre 1989 y 2011, está obligada a dirigirse a las estadísticas proporcionadas por cuatro organismos distintos. Esta indeseable fragmentación quedó parcialmente resuelta con la creación de un Gabinete de Coordinación y Estudios que, fue el responsable de crear el Sistema Estadístico de Criminalidad (SEC), a partir del cual se gestionaría la Estadística Nacional de Criminalidad (RD 400/2012). Esta actuación, además de realizarse con una inexplicable demora, representa una acción incompleta, en tanto no ha subsanado la segmentación de las dos décadas precedentes y, tal y como señala la Ley 12/1989 de la Función Estadística Pública incumple el criterio de facilitar "la comparación temporal y espacial de los datos que se

${ }^{3}$ El INE también difunde una selección de estadísticas de criminalidad, colaborando en la tarea de difusión pública de cifras y datos de interés general.

${ }^{4}$ En la actualidad, se pueden consultar on-line todos los Anuarios, a través de la website ministerial disponible a través de la siguiente dirección URL http://www.interior.gob.es/

${ }_{5}$ El Real Decreto 400/2012, de 17 de febrero, por el que se desarrolla la estructura orgánica del Ministerio del Interior BOE núm. 42, de 18 de febrero de 2012, páginas 14527 a 14553.

${ }^{6}$ La creación del Sistema Estadístico de Criminalidad (SEC) vino precedida por la creación, en el año 2007, del Gabinete de Estudios de Seguridad Interior (GESI), hoy denominado Gabinete de Coordinación y Estudios de la Secretaria de Estado de Seguridad (GCESES).

7 En el caso de la Policía Autónoma Vasca (PAV), las estadísticas MIR incorporan los datos desde el año 1998. 
publican", por lo que queda pendiente acometer la integración de las estadísticas de las policías autonómicas con carácter retroactivo. La detección de errores y su rápida corrección y comunicación, tal y como reconoce el INE, debería ser una práctica ineludible para garantizar la calidad de la información estadística de interés general (INE 2014: 4).

El término 'accesibilidad' hace referencia a la posibilidad de la descarga automática de la información estadística (datos y metadatos) en formatos que permitan su reconocimiento en diversos paquetes de software, facilitando a las personas usuarias su posterior utilización y análisis. En esta dimensión también el Ministerio del Interior ha actuado con negligencia, pues sólo a partir del año 2012, la website ministerial empezó a proporcionar los datos contenidos en el Anuario en lo que denominó 'formato reutilizable', que consistía en transferir el documento a un impracticable fichero en formato 'Excel', con una matriz de más de 900 páginas, a las que había que eliminar todos los formatos de edición, si se pretendía operar estadísticamente con las cifras. El fichero carecía de descarga selectiva y había una ausencia total de hipervínculos para navegar de forma estratégica por áreas temáticas. No sería hasta el año 2015 cuando, con la creación del Portal Estadístico de Criminalidad ${ }^{8}$, se produjera un tímido avance en el servicio de almacenamiento digital de estadísticas de criminalidad, facilitando la búsqueda, consulta y descarga de indicadores sobre delincuencia. Esta herramienta virtual permite elaborar 'tablas dinámicas' o, si se prefiere, tablas 'a medida' en función de los intereses de las personas usuarias, pero y, quizá por su corta trayectoria, las variables disponibles para consulta y descarga son aún muy limitadas?.

El término 'claridad conceptual' hace referencia a la precisión semántica y metodológica de las variables e indicadores incluidos en la estadística y afecta al alcance de las definiciones y las clasificaciones de las infracciones, pero también refleja la huella androcéntrica en el marco jurídico penal ${ }^{10}$. La Ley Orgánica 3/1989 de actualización del Código Penal ordenó sustituir la expresión 'delitos contra la honestidad' por 'delitos contra la libertad sexual', ya que es la libertad

\footnotetext{
${ }^{8}$ La dirección electrónica de acceso a esta herramienta es https://estadisticasdecriminalidad. ses.mir.es/

${ }^{9}$ El Portal Estadístico de Criminalidad permite acceder a las series anuales de hechos conocidos combinando tres dimensiones: ámbito territorial (Total nacional, Comunidades Autónomas, Provincias, Ciudades autonómicas), tipología penal (44 tipos y subtipos delictivos definidos por el Código Penal) y ámbito temporal (2010-2018).

${ }_{10}$ Hasta 1989 el Código Penal español, como otras leyes en Europa, refería la violencia sexual como "delitos contra la honestidad", es decir, los hechos atentaban contra el pudor de las mujeres, mancillando su principal cualidad, 'la castidad', que había de reservarse para el esposo o conservarse para la vida religiosa (Vigarello 1999: 338 y Nuñez Fernández 2010). De este modo, se atacaba no el cuerpo, sino la honra (Segato 2003: 143), quedando en el caso de ser 'doncellas' estigmatizadas e impuras y, no sólo ellas, la deshonra se extendía a su linaje, especialmente si la familia ostentaba una alta posición de clase (Rodríguez Ortiz 2003). Señala Jimeno de Torres (1980: 443-446) que desde el primer Código Penal español (1822) se reprodujeron, de forma mimética, los preceptos en lo que a esta tipología penal se refiere (1848, 1850, 1870, 1928, 1932, 1944 y 1971).
} 
el bien jurídico atacado ${ }^{11}$. En la misma dirección, la Ley Orgánica 10/1995 extiende la protección a todas las personas y no exclusivamente a la mujer como sujeto vulnerable. Una cuestión de gran trascendencia para el reconocimiento de este crimen también ejercido contra varones (Segato 2003).

Actualmente, la estadística de criminalidad relativas a la rúbrica de violencia sexual sigue, parcialmente, las categorización establecida en el Código Penal vigente, pero sin respetar todos los subtipos delictivos que aquél establece, de forma que los datos oficiales disponibles muestran una excesiva agregación de los delitos sancionados por el Título VIII; mientras el Código Penal delimita nueve subcategorías delictivas, el Anuario se limita a proporcionar cuatro rúbricas de clasificación (Tabla 1). Por su parte, el Portal Estadístico de Criminalidad dispone de cinco categorías al distinguir Agresión sexual y, Agresión sexual con penetración.

Tabla 1: Comparativa entre las tipologías delictivas definidas en el Código Penal y las categorías de clasificación de la estadística de delincuencia sexual.

Tipologías delictivas según el Código Penal
Categorías de clasificación de la delincuencia sexual Anuario Estadístico MIR

\begin{tabular}{|c|c|}
\hline $\begin{array}{l}\text { 1. Agresiones sexuales (art. 178- } \\
180 \text { ) }\end{array}$ & 1. Agresión sexual con penetración \\
\hline \multicolumn{2}{|l|}{ 2. Abusos sexuales (art. 180-182) } \\
\hline \multicolumn{2}{|l|}{$\begin{array}{l}\text { 3. Abusos y agresiones sexuales a me- } \\
\text { nores de } 16 \text { años (art. 183) }\end{array}$} \\
\hline 4. Acoso sexual (art. 184) & \multirow{5}{*}{ 2. Otros contra la libertad sexual } \\
\hline 5. Exhibicionismo (art. 185) & \\
\hline 6. Provocación sexual (art. 186) & \\
\hline $\begin{array}{l}\text { 7. Prostitución y explotación sexual (art. } \\
\qquad 187 \text { ) }\end{array}$ & \\
\hline $\begin{array}{l}\text { 8. Prostitución y explotación sexual de } \\
\text { menores o personas con discapacidad } \\
\text { (art. 188) }\end{array}$ & \\
\hline \multirow[t]{2}{*}{$\begin{array}{l}\text { 9. Corrupción de menores o personas } \\
\text { con discapacidad (art. 189) }\end{array}$} & $\begin{array}{l}\text { 3. Corrupción de menores o inca- } \\
\text { pacitados }\end{array}$ \\
\hline & 4. Pornografía de menores \\
\hline
\end{tabular}

Fuente: Código Penal 2015 y Anuario Estadístico MIR 2018 - Elaboración propia

${ }^{11}$ Con este giro lingüístico se va a consolidar, al menos en el texto de la ley, el pleno derecho de las mujeres, a la autonomía y autodeterminación sobre sus cuerpos. 
Este exceso de agregación de los subtipos penales es un problema metodológico que, como señala el Instituto Europeo para la Igualdad de Género (EIGE 2013), se realiza de forma generalizada en otros países de la Unión Europea. La primera consecuencia directa de esta deficiencia es que impide una visión descriptiva completa de las formas que adoptan las violencias sexuales reconocidas por el Código Penal ${ }^{12}$.

El segundo problema que se deduce al examinar los criterios de clasificación es que, en función de la fuente consultada, Anuario MIR o Portal Estadístico, se obtienen conclusiones disímiles. La distribución proporcionada por el Anuario condiciona una ilusoria percepción de seguridad, puesto que la 'agresión sexual con penetración', el subtipo delictivo más grave, sólo representa el 12 por ciento del conjunto de infracciones denunciadas contra la libertad sexual, pudiendo apreciarse inicialmente como un suceso poco importante. En cambio, bajo la difusa categoría de 'Otros delitos contra la libertad/indemnidad sexual' se encuentra el 78 por ciento de las denuncias (Tabla 2). Por su parte, el Portal Estadístico de Criminalidad publica una rúbrica más y la suma de las categorías 'Agresión sexual' y 'Agresión sexual con penetración' superan el 25 por ciento de los delitos denunciados contra la libertad sexual.

Tabla 2: Magnitudes de la criminalidad sexual según subtipos delictivos, 2018.

\begin{tabular}{|l|l|l|l|l|}
\hline $\begin{array}{l}\text { Delitos contra la libertad e indem- } \\
\text { nidad sexual (Hechos conocidos) }\end{array}$ & Anuario & $\%$ & $\begin{array}{l}\text { Portal } \\
\text { EC }\end{array}$ & $\%$ \\
\hline Agresión sexual & - & - & 1.917 & 13,91 \\
\hline Agresión sexual con penetración & 1.700 & 12,33 & 1.700 & 12,33 \\
\hline $\begin{array}{l}\text { Corrupción de menores o incapaci- } \\
\text { tados }\end{array}$ & 268 & 1,95 & 268 & 1,94 \\
\hline Pornografía de menores & 892 & 6,47 & 892 & 6,47 \\
\hline $\begin{array}{l}\text { Otros contra la libertad/indemnidad } \\
\text { sexual }\end{array}$ & 10.922 & 79,25 & 9.005 & 65,34 \\
\hline Total & 13.782 & $100 \%$ & 13.782 & $100 \%$ \\
\hline
\end{tabular}

Fuente: Anuario Estadístico MIR y Portal Estadístico de la Criminalidad 2018 - Elaboración propia

${ }^{12}$ No es objeto de este artículo reflexionar sobre la ambivalencia entre la carga semántica que denomina el título VIII del Código Penal: 'Delitos contra la libertad e indemnidad sexuales' y que debería tener por criterio sancionar infracciones producidas por actos sexuales no deseados (juzgar si hubo o no hubo consentimiento), en vez de emplear en la interpretación de la ley penal la deliberación sobre la presencia/ausencia de violencia física hacia la víctima y la resistencia/no resistencia de la víctima, como ocurrió en la sentencia del caso 'San Fermín 2016’(SAP NA 86/2018). 
A estas deficiencias habría que sumar la ruptura en los criterios de establecimiento de categorías de clasificación, asociadas con subtipos delictivos. Entre 1989 y 2018, los Anuarios MIR han modificado, hasta en siete ocasiones, los epígrafes que refieren la criminalidad sexual. En la tabla 3 se ilustra la volatilidad de las rúbricas y su zigzagueante trayectoria advirtiéndose avances e inexplicables retrocesos. Hasta 1997, cuando la estadística ajusta las categorías a la reforma de Código Penal ya mencionada, se observa la pervivencia de términos anacrónicos como 'estupro', 'incesto' y 'rapto' que describían de forma semántica la relación entre víctima y victimario. Esta imprecisa forma de caracterizar el vínculo permitía, no obstante, advertir la incidencia de las violencias sexuales entre personas con una relación habitual; un aspecto que la estadística actual no contempla y es una de las omisiones más urgentes por subsanar según la Recomendación General núm. 19 del Comité CEDAW, de 29 de julio de 2015, párrafo 21 , letra f) que demanda "Recopilar datos estadísticos sobre la violencia doméstica y sexual desglosados por sexo, edad, nacionalidad y relación entre la víctima y el autor".

Tabla 3: Variaciones en las categorías de clasificación de la criminalidad sexual consignadas en los Anuarios MIR, 1989-2018.

\begin{tabular}{|c|l|c|}
\hline Anuario & \multicolumn{1}{|c|}{ Categorías de clasificación consignadas } & $\begin{array}{c}\text { Núm. cate- } \\
\text { gorías }\end{array}$ \\
\hline 1989 & Violaciones & 1 \\
\hline $1990-1992$ & $\begin{array}{l}\text { Violaciones, Otros delitos contra la libertad } \\
\text { sexual }\end{array}$ & 2 \\
\hline 1993 & $\begin{array}{l}\text { Violaciones, Agresión sexual, Exhibicionismo } \\
\text { y provocación sexual, Estupro, Incesto, Corrup- } \\
\text { ción de menores, Rapto, Proxenetismo, Trata de } \\
\text { blancas, Otros relativos a la prostitución }\end{array}$ & 10 \\
\hline $1994-1995$ & $\begin{array}{l}\text { Violaciones } \\
1996\end{array}$ & $\begin{array}{l}\text { Violaciones, Agresión sexual, Acoso y abuso } \\
\text { sexual, exhibicionismo, estupro, incesto, co- } \\
\text { rrupción de menores, Otros relativos a la pros- } \\
\text { titución }\end{array}$ \\
\hline $1997-2006$ & $\begin{array}{l}\text { Agresión sexual, Agresión sexual con penetra- } \\
\text { ción, Abuso sexual, Abuso sexual con penetra- } \\
\text { ción, Acoso sexual, Exhibicionismo, Provoca- } \\
\text { ción sexual, Corrupción menores-incapacitados, } \\
\text { Coacción a la prostitución, Pornografía de } \\
\text { menores }\end{array}$ & 8 \\
\hline
\end{tabular}




\begin{tabular}{|c|c|c|}
\hline Anuario & Categorías de clasificación consignadas & $\begin{array}{c}\text { Núm. cate- } \\
\text { gorías }\end{array}$ \\
\hline $2007-2011$ & $\begin{array}{l}\text { No se desagrega ninguna categoría de criminali- } \\
\text { dad sexual pues toda la delincuencia se conden- } \\
\text { sa en cuatro epígrafes: 1) Delitos contra la vida, } \\
\text { la integridad y la libertad de las personas 2) De- } \\
\text { litos contra el patrimonio, 3) Faltas de lesiones } \\
\text { y 4) Faltas de hurto }\end{array}$ & 0 \\
\hline $2012-2018$ & $\begin{array}{l}\text { Agresión sexual con penetración, Corrupción de } \\
\text { menores o incapacitados, Pornografía de meno- } \\
\text { res, Otros contra la libertad e indemnidad sexual }\end{array}$ & 4 \\
\hline
\end{tabular}

Fuente: Anuarios Estadísticos MIR (varios años) - Elaboración propia

La falta de coincidencia en las categorías de clasificación no es un asunto menor, pues reduce la descripción cuantitativa sobre las diversas formas de violencia sexual e impide crear series temporales y estudiar la evolución de los subtipos delictivos a medio y largo plazo. La estructura de sistematización de la información sólo permite reconstruir la evolución del agregado total de 'delitos contra la libertad sexual' y diferenciar, exclusivamente, la evolución de las violaciones. Este cambio en los criterios de elaboración de la estadística es un claro retroceso en la calidad y alcance de los datos oficiales.

Más problemática resulta la singularísima utilización del concepto de 'victimización' que hace referencia "al número de hechos denunciados por personas en los cuales manifiestan ser víctimas o perjudicados con ocasión de alguna infracción penal. Se diferencia del concepto de víctima, ya que este determina a personas individuales" (Anuario MIR 2015: 427; 2016: 333; 2017: 186 у 2018: 186). A la farragosa definición de victimización le sigue el siguiente ejemplo: "Las diferencias entre victimización y víctima se pueden ejemplificar con el siguiente supuesto: Una persona presenta una denuncia y manifiesta que, en un determinado periodo de tiempo, ha sido objeto de 3 hechos de malos tratos en el ámbito familiar y un delito de amenazas. Además, en esa misma denuncia manifiesta que su hijo de tres años también ha sido objeto de malos tratos en una ocasión. Total de denuncias 1. Total de víctimas 2. Total de victimizaciones 5 (3 hechos de malos tratos a la mujer +1 delito de amenazas hacia la mujer + 1 hecho de malos tratos hacia el niño".

Esta forma de definir las victimizaciones y omitir a las víctimas produce, en nuestra opinión, varios efectos negativos: a) la objetualización de las víctimas, b) la identificación de las 'victimizaciones', como delitos imputables y no suje-

${ }^{13}$ Esta tragedia estadística quedó parcialmente subsanda cuando el Anuario 2012 incorporó una evolución de la criminalidad sexual entre 2007 y 2011 siguiendo los criterios establecidos por el Sistema Estadístico de Criminalida (SEC). 
tos, conlleva un artificioso sobreregistro y, lo que es más grave, c) la variable 'victimizaciones' impide establecer cruces entre personas víctimas y sus características sociodemográficas. Con todo, existen también aspectos ajenos al SEC, de carácter normativo, que representan una ruptura en la comparabilidad de las series temporales. Tras la última reforma del Código Penal, en el año 2015, los Anuarios MIR dejan de diferenciar 'delitos' y 'faltas', clasificando todas las denuncias bajo el epígrafe 'infracciones', criterio que supone una quiebra sustantiva con las estadísticas precedentes, impidiendo una perspectiva de análisis comparada en el tiempo y una pérdida de información relevante en el estudio de la delincuencia ${ }^{14}$.

Por último, el tercer criterio enunciado para la evaluación de la calidad de la estadística de criminalidad sexual hace referencia a las 'variables de estudio', es decir, los indicadores incluidos y sus potencialidades de asociación. En este aspecto debemos hacer referencia a la escasez de variables disponibles. La primera información relevante que proporciona el Anuario es la cifra del delito registrado, diferenciando entre tres categorías: 'Hechos conocidos', 'Hechos esclarecidos' y 'Detenciones e imputaciones' (Anuario MIR 2015: 427) ${ }^{15}$. Esta información sobre la clasificación de denuncias, según tipo delictivo, está disponible para el total nacional y aparece también desagregada por Comunidades Autónomas y provincias ${ }^{16}$. No obstante, no se garantiza una correspondencia entre dichas rúbricas, es decir, los 'hechos esclarecidos' no tienen porqué estar referidos al año en el que fueron registrados (hechos conocidos) y, mucho menos a las detenciones efectuadas en ese período ${ }^{17}$. Esta cuestión aconseja tomar como dato más consistente los 'Hechos conocidos', es decir, las denuncias.

${ }^{14}$ La reforma del Código Penal, LO 1/2015, de 30 de marzo, en su afán punitivista conllevó la transformación de un grupo de 'faltas' en 'delitos leves' e 'infracciones administrativas', cuestión que condicionó al Gabinete de Coordinación y Estudios a unificar bajo el mismo epígrafe de 'infracciones' (delitos + faltas) las diferentes tipologías penales.

15 "Por hechos conocidos se entienden el conjunto de infracciones penales y administrativas, que han sido conocidas por las distintas Fuerzas y Cuerpos de Seguridad, bien por medio de denuncia interpuesta o por actuación policial realizada motu proprio (labor preventiva o de investigación). Los hechos esclarecidos se clasifican como tales cuando en el hecho se dan las siguientes circunstancias: - Detención del autor «in fraganti»; - Identificación plena del autor, o alguno de los autores, sin necesidad de que esté detenido, aunque se encuentre en situación de libertad provisional, huido o muerto; - Cuando exista una confesión verificada, pruebas sólidas o cuando haya una combinación de ambos elementos; - Cuando la investigación revele que, en realidad, no hubo infracción... La detención alcanza la lectura de derechos de la persona física, privándole de libertad y poniéndolo a disposición judicial, por atribuirle la comisión de una infracción penal".

${ }_{16}$ También se incluyen datos de criminalidad para capitales de provincia y municipios de más de 50.000 habitantes, aunque esta estadística sólo comunica grandes indicadores de criminalidad, siguiendo los criterios de clasificación internacional de Naciones Unidas (ICCS): Homicidios Dolosos y Asesinatos consumados (EU), Robo con Violencia e Intimidación (EU), Robos con Fuerza en Domicilios (EU), Sustracción Vehículos a Motor (EU), Tráfico de Drogas (EU), Daños y Hurtos. Esta clasificación impide, en el caso que nos ocupa -delitos contra la libertad e indemnidad sexual-, un análisis de datos por capitales y municipios de más de 50.000 habitantes.

${ }^{17}$ Asimismo, se debe tener en cuenta que menos de la mitad de las denuncias por delitos contra la libertad sexual acaban iniciando un proceso judicial. 
Hasta aquí, hemos identificado algunas de las deficiencias de la estadística producida y difundida por el Ministerio del Interior pero nada se ha dicho de la presentación de las magnitudes. Las cifras publicadas refieren datos absolutos, cuestión que problematiza su comparabilidad, pues existe una variable distribución de la población en el territorio ${ }^{18}$. De modo que las provincias y Comunidades Autónomas con una alta densidad demográfica, como por ejemplo, Madrid y Barcelona, son también hegemónicas en el registro de infracciones penales, sin que por ello su nivel de delincuencia sea superior a otros territorios. La transformación de los datos absolutos en datos relativos mediante el cálculo de 'tasas' es una operación estadística básica e imprescindible que posibilita la comparabilidad de cifras, bien en distintos territorios geográficos, bien en su evolución temporal o, considerando ambos criterios de manera simultánea ${ }^{19}$.

Para ilustrar el argumento, hemos calculado la tasa específica de criminalidad, para el subtipo delictivo de 'agresión sexual con penetración'; en el numerador hemos empleado el registro de 'hechos denunciados-hechos conocidos' y en el denominador hemos usado las estimaciones provinciales de población actualizadas que proporciona el INE. El resultado se presenta ordenado, de mayor a menor, y expresa el número de 'agresiones sexuales con penetración' denunciadas por cada 100.000 habitantes $^{20}$. De esta manera, podemos apreciar que los máximos, en términos absolutos, de Barcelona (345 denuncias) y Madrid (252) no se corresponden con tasas de criminalidad más altas (Tabla 4).

18 De forma excepcional los Anuarios MIR pueden incorporar el cálculo de tasas, como por ejemplo en 1993 publicaron la Tasa de denuncia por cada mil vehículos de parque o, en 1997 se puede consultar la Tasa de inseguridad ciudadana: por provincia (Pág. 113) y en los Anuarios posteriores pueden aparecer refrencias a las tasas en CCAA o el total nacional.

${ }^{19}$ Una 'tasa' relaciona la frecuencia con la que se produce un fenómeno y la población total de referencia, transformando la unidad de medida original en un valor relativo, referido a una misma cantidad de población - unidades-. En el ámbito de la seguridad ciudadana, las tasas de criminalidad expresan las infracciones penales por cada mil habitantes.

${ }^{20}$ Si bien las tasas de criminalidad general se calculan sobre 1.000 habitantes, en el caso de delitos con menor incidencia se emplean otros criterios. En este caso hemos seguido el criterio empleado por Eurostat para el cálculo de tasas específicas de violencia sexual, infracciones registradas por cada 100.000 habitantes. 
Tabla 4: Tasas de ‘agresión sexual con penetración’ según provincias (2018).

\begin{tabular}{|c|c|c|c|c|c|}
\hline Provincia & $\begin{array}{c}\text { Tasa } \\
\text { A.S.c P. }\end{array}$ & Provincia & $\begin{array}{c}\text { Tasa } \\
\text { A.S.c P. }\end{array}$ & Provincia & $\begin{array}{c}\text { Tasa } \\
\text { A.S.c P. }\end{array}$ \\
\hline Girona & 6,96 & Álava & 3,34 & Málaga & 2,19 \\
\hline Lleida & 6,93 & Zaragoza & 3,25 & León & 1,94 \\
\hline Illes Balears & 6,47 & Murcia & 3,11 & Córdoba & 1,91 \\
\hline Barcelona & 6,15 & Albacete & 3,09 & Castellón & 1,91 \\
\hline Ceuta & 5,87 & Toledo & 3,06 & A Coruña & 1,79 \\
\hline Gipuzkoa & 5,83 & Granada & 2,74 & Burgos & 1,68 \\
\hline Navarra & 5,56 & Valladolid & 2,69 & Asturias & 1,65 \\
\hline Bizkaia & 5,05 & Pontevedra & 2,65 & Guadalajara & 1,57 \\
\hline Tarragona & 5,03 & Cádiz & 2,58 & Cáceres & 1,51 \\
\hline Las Palmas & 4,78 & Ávila & 2,52 & Lugo & 1,51 \\
\hline Cuenca & 4,56 & Palencia & 2,47 & Cantabria & 1,38 \\
\hline Zamora & 4,01 & Salamanca & 2,41 & Huelva & 1,35 \\
\hline Madrid & 3,83 & Sevilla & 2,32 & Ciudad Real & 1,20 \\
\hline Alicante & 3,81 & Melilla & 2,32 & Huesca & 0,91 \\
\hline Promedio & 3,63 & Ourense & 2,26 & Segovia & 0,00 \\
\hline $\begin{array}{c}\text { Sta. Cruz Tene- } \\
\text { rife }\end{array}$ & 3,44 & Badajoz & 2,22 & Soria & 0,00 \\
\hline Valencia & 3,41 & La Rioja & 2,22 & Teruel & 0,00 \\
\hline Almería & 3,38 & Jaén & 2,19 & & \\
\hline
\end{tabular}

Fuente: Portal Estadístico de Criminalidad y estimaciones de población INE 2018 - Elaboración propia

Asimismo, es necesario señalar, en la estadística de delitos sexuales registrados, la insuficiencia de variables de análisis, es decir, las variables e indicadores que permitan contextualizar las infracciones. Por el momento, el banco de datos disponible sólo caracteriza el sexo, la nacionalidad y la edad ${ }^{21}$. La escasa información suministrada impide conocer cuestiones tan importantes como identificar la relación entre víctima y su agresor(es), la reiteración del delito, el contexto

${ }^{21}$ La arbitrariedad a la hora de adoptar criterios de agregación de las variables resulta una constante en los Anuarios MIR, de forma que los intervalos de edad que permiten clasificar las victimizaciones han cambiado con el paso del tiempo lo que impide establecer comparaciones. En 2005 se muestran diez intervalos <13, 13-15, 16-17, 18-20, 21-30, 31-40, 41-50, 51-64, >64 y 'Edad desconocida'; mientras que a partir de 2012 se establecen siete intervalos: 0-13, 14-17, 18-30, 31-40, 41-64, >64 y 'Edad desconocida'. 
espacio-temporal de la violencia o, las agresiones sexuales con más de un perpetrador, o sea, las agresiones en grupo.

Una estadística con tan pocas variables de análisis impide conocer el contexto e incidencia de las tipologías en que se producen las violencias sexuales, por ejemplo, cuál es la importancia de la violación marital, de las agresiones dentro de la pareja o, los supuestos de violencia sexual en el ámbito de las relaciones de parentesco, redes de amistad o entornos institucionalizados (centros educativos, organizaciones deportivas, etc.). Estos elementos son fundamentales para el posterior desarrollo en el diseño de políticas públicas de sensibilización e intervención.

A modo de síntesis, las estadísticas oficiales sobre criminalidad sexual, producidas en España mediante registro de denuncias y difundidas por el Ministerio del Interior presentan una calidad deficiente. Si bien la formación del GESI en 2007 y la creación del SEC en 2012 son, acciones positivas en la centralización de las cifras de criminalidad, siguen siendo acciones incompletas. El examen del cumplimiento de todos los criterios esenciales (disponibilidad y accesibilidad, claridad conceptual y variables de estudio) para garantizar la calidad de las estadísticas resulta aún insuficiente para acometer con un mínimo rigor el estudio cuantitativo de la violencia sexual en España.

\subsubsection{Estadísticas judiciales y penitenciarias}

La estadística judicial es elaborada y difundida por el Consejo General del Poder Judicial (CGPJ) que informa de forma trimestral del número de asuntos ingresados, resueltos y pendientes; así como de las sentencias y de autos emitidos. La publicación La Justicia Dato a Dato es el documento anual de síntesis y proporciona una radiografía de la actividad realizada desde el sistema judicial en el año de referencia. Sin embargo, aunque los informes contemplan secciones específicas sobre violencia de género y violencia doméstica, no existe ningún dato específico sobre delincuencia sexual.

Merced a la reciente concienciación social del suceso, la última Memoria de la Fiscalía General del Estado (2019), reconoce de forma específica el 'inquietante' aumento de la criminalidad sexual, de forma general supone un 28 por ciento, respecto al año anterior ${ }^{22}$. En la Memoria se destaca la preocupación por el crecimiento significativo de abusos sexuales por menores (XXVIII) y el incremento de los delitos de pornografía infantil (XXXIX).

Por su parte, la estadística penitenciaria se elabora y coordina por el Sistema de Información Penitenciaria (SGIP) desde la Secretaría General del Institu-

${ }^{22}$ La Fiscalía señala la siguiente evolución de casos contra la libertad sexual: En 2015 se atendieron 1.081 asuntos, en 20161.271 y en 2017 1.386. No obstante la Memoria (2019: 679) aclara que el incremento se debe al crecimiento de delitos de abuso sexual y no de agresión sexual; añadiendo que la variación de las cifras guarda relación con la reforma de Código Penal, que aumentó de trece a dieciséis años la edad para prestar consentimiento en las relaciones sexuales. 
ciones Penitenciarias, dependiente del Ministerio del Interior. El SGIP informa mensualmente de las variaciones de la población reclusa por centros de internamiento $^{23}$. La síntesis estadística está disponible en los Informes Generales de la Administración Penitenciaria, de los que se conoce que el porcentaje de varones privados de libertad por delitos contra la libertad sexual representa el 6,8\% del total de reclusos, mientras que las mujeres privadas de libertad por este mismo delito representan el 1,3\% sobre el total de reclusas (IGAP 2018: 24-27) ${ }^{24}$.

En resumen, las estadísticas judiciales y penitenciarias contienen escasas referencias a la incidencia de la violencia sexual, cuestión que deberá ser subsanada con urgencia, ahora que la ciudadanía empieza a reconocer la gravedad de este tipo delictivo en la sociedad española.

\subsection{La Investigación Social por Encuesta y las Encuestas de Victimización}

La Investigación Social por Encuesta (ISE) es una de las principales técnicas para producir información mediante la aplicación de un cuestionario de interrogación estandarizado a un subconjunto de población, llamado muestra (Leeuw, Hox y Dillman 2008: 2-4). La principal ventaja que justifica su empleo masivo es que, a partir de una muestra probabilística, relativamente reducida, se pueden estimar las opiniones, actitudes y comportamientos de un universo significativamente mayor ${ }^{25}$.

En el ámbito de la Criminología, la importancia de la encuesta, como técnica de producción de datos, ha estado orientada a estimar dos dimensiones diferenciadas: 1) Qué porcentaje de población ha sido víctima de algún delito -Encuestas de Victimización (EV)- y 2) Cuál es la percepción subjetiva de seguridad en la población de referencia, tratando de identificar qué categorías poblacionales declaran tener más miedo a determinadas infracciones (Caro y Navarro 2017). En este artículo nos centraremos de forma exclusiva en las EV por su especificidad en la estimación cuantitativa de la criminalidad real.

La utilidad de las Encuestas de Victimización es determinante en el conocimiento e intervención de los fenómenos delictivos, puesto que las estadísticas de

${ }^{23}$ Los datos estadísticos son accesibles desde la siguiente dirección URL http://www.institucionpenitenciaria.es/web/portal/index.html

${ }^{24}$ En términos absolutos, la población de varones encarcelados por delitos contra la libertad sexual es de 3.149 sobre un total de 46.669. En el caso de las mujeres, las cifras registran 48 victimarias sobre 3.792 reclusas.

${ }^{25}$ En nuestro país, muchas informaciones estratégicas, como por ejemplo las tasas de ocupación y paro, se contabilizan a partir de esta técnica de investigación social. Veamos un ejemplo, la Encuesta de Población Activa (EPA) es una de las Operaciones Estadísticas más importantes del Sistema Estadístico Nacional. La EPA estima, que no contabiliza, las magnitudes de población ocupada y parada en España. La muestra inicial es de unas 65.000 familias, al trimestre, que equivalen aproximadamente a 160.000 personas, sobre una base poblacional de más de 40 millones de unidades. 
criminalidad, elaboradas mediante el registro de las denuncias, no tienen capacidad para reflejar la delincuencia real ${ }^{26}$. Diversas publicaciones reconocen que las estadísticas policiales y judiciales no permiten conocer la delincuencia real de un territorio, en tanto que existe un porcentaje de infracciones no denunciadas, ni sancionadas (Biderman y Reiss 1967; Alvira y Rubio 1982; García España et al. 2010: 5; Pérez y Benito 2013: 2-8), es por ello por lo que, las EV se consideran una herramienta imprescindible para estimar la magnitud de víctimas de algún delito (Pérez y Benito 2013: 3) ${ }^{27}$.

En el caso de la criminalidad sexual, la utilidad de las EV es todavía mayor, puesto que las investigaciones empíricas coinciden en afirmar que este tipo penal es el que presenta la más baja propensión a denunciar de todas las infracciones sancionables (Von Hofer 2000: 85; Marín 2006: 17; van Dijk et al. 2007: 109; Macdowall et al. 2013: 1851; EIGE 2013) ${ }^{28}$. La quinta edición del European Sourcebook of Crime and Criminal Justice Statistics estima que el promedio en la propensión a denunciar la agresión sexual es del 17 por ciento (HEUNI 2014: 350). La Encuesta sobre Violencia de Género, realizada por la Agencia Europea de Derechos Fundamentales (FRA) en el año 2014, sobre la base de una muestra probabilística de 42.000 mujeres residentes en los 28 Estados miembros de la Unión Europea, reveló que la propensión a notificar a la policía este delito oscila entre 25 - 30 \% (FRA 2014: 3). En Gran Bretaña, según los resultados publicados por Macdowall et al. (2013), la propensión a denunciar se situaría en el $10 \%$ de las víctimas, apreciándose diferencias según el sexo ${ }^{29}$. En Francia, una reciente investigación por encuesta señala que la violación es un crimen

${ }^{26}$ En el ámbito de la Criminología la distancia entre 'delincuencia real' y 'delincuencia registrada' se ha venido denominando 'cifra negra' (Dark Figure of Crime) y la diferencia o brecha varía en función del tipo de delito (Biderman y Reiss 1967).

${ }^{27}$ El empleo de la encuesta como instrumento de estimación de la delincuencia tuvo experiencias tempranas en algunos territorios escandinavos (van Dijk 2015: 12), aunque, según una reciente publicación, no fue la criminóloga finlandesa Inkeri Antilla la persona que ideó usar la encuesta como técnica de investigación social para estimar el delito no registrado; Jan van Dijk (2015: 1011) refuta este mito, aunque sí señala diversas experiencias escandinavas en la temprana aplicación de cuestionarios para estimar víctimas la delincuencia. La extensión y perfeccionamiento de las EV se desarrolló en Estados Unidos en la década de los años sesenta, cuando se inició la aplicación de cuestionarios estructurados para conocer el alcance real de las infracciones (Gondra 2008: 94). En España, la primera Encuesta de Victimización se produce en 1978 (Alvira y Rubio 1982: 30).

${ }^{28}$ Las razónes barajadas por los especialistas para explicar el alto grado de inhibición de las victimas de violencia sexual guarda relación con factores como: miedo al agresor, sentimiento de vergüenza, miedo a no ser creídas, temor a las revictimizaciones, falta de información sobre qué hacer ante una agresión sexual (Regan y Kelly 2003 y DGVG 2018).

${ }^{29}$ Los análisis publicados por Wendy Macdowall et al. (2013), sobre la tercera edición de la Encuesta británica sobre Actitudes hacia la sexualidad y estilos de vida (Sexual Health Attitudes and Lifestyles -Natsal-3), concluyen que, de las personas que informaron de haber completado sexo sin consentimiento, menos de la mitad le contaron a otra persona lo sucedido, siendo las mujeres más propensas a contarlo que los varones $(42.2 \%$ de las mujeres frente a $32.6 \%$ de los hombres). Las mujeres también denunciaron más los hechos (12,9\% de mujeres frente a 8,0\% de hombres). La tendencia a denunciar aumenta cuanto más jóvenes son las víctimas y, sobre todo, cuando el victimario era un extraño (20,9\% de propensión a denunciar cuando no existe vínculo con la víctima frente al 9,4\% cuando el victimario era pareja o expareja). 
habitual que afecta, cada año, a decenas de miles personas y, aproximadamente, una de cada diez víctimas denuncia (HCE, 2016:16). En España, las dos últimas ediciones de la Macroencuesta de Violencia contra la Mujer (2015 y 2019) han incluido ítems para medir la incidencia de la violencia sexual ${ }^{30}$. Según los datos recabados por la Macroencuenta, en 2015, sólo el 6 por ciento de las víctimas de una vilación interpone una denuncia (Domenech y Sirvent, 2017) y en la edición 2019 se refleja que, sólo el 8 por ciento de las mujeres que han sufrido violencia sexual fuera de la pareja ha denunciado los hechos. Este porcentaje se eleva al $11,1 \%$ si se tienen en cuenta también las denuncias interpuestas por otra persona o institución.

Para contextualizar mejor estos datos y, teniendo en cuenta los resultados de diversas EV de ámbito nacional (Estudio CIS núm. 2284 -1998 y Estudio CIS 2315 - 2004) la propensión general a interponer una denuncia cuando se ha sido víctima de un delito, cualquiera que sea, puede oscilar entre el $64 \%$ (1998) y el $55,8 \%(2004)^{31}$, lo que evidencia el enorme subregistro de los delitos contra la libertad sexual, en relación con la delincuencia general. Por tanto, la ocultación generalizada de estos delitos no sólo es un hecho verificado sino que 'se da por hecho' su silenciamiento. Los resultados de la pregunta 10 de la encuesta sobre Percepción social de la violencia sexual (2017, Estudio CIS núm. 3182): “ ¿Cree Ud. que las mujeres que sufren una agresión sexual lo denuncian?" (Tabla 5), señalan que la mayoría de la población española manifiesta que las agresiones sexuales se denuncian 'En pocas ocasiones' (61,7\%). Esta percepción difiere según el sexo; si agrupamos las categorías 'En pocas ocasiones' y 'Casi nunca' se advierte que las mujeres piensan que la violencia sexual se denuncia muy poco, un $74 \%$, frente a un $67 \%$ en los varones ${ }^{32}$.

${ }^{30}$ En el año 2015, el cuestionario de la Macroencuesta se modificó de forma relevante en relación con las ediciones anteriores $(1999,2002,2006,2011)$. Con este cambio, que principalmente tomó como referencia las Directrices elaboradas por la División de Estadística de las Naciones Unidas, se buscó medir con más rigor la realidad de la violencia contra la mujer en España. En la última edición (2019) se ha continuado este proceso de mejora de la calidad de la encuesta. Se ha tomado como punto de partida el cuestionario de 2015, que ha sido ampliado para poder capturar más dimensiones de la violencia, cumpliendo todos los requerimientos estadísticos del Convenio del Consejo de Europa sobre Prevención y Lucha contra la Violencia contra las Mujeres y la Violencia Doméstica (Convenio de Estambul, 2014) y dando respuesta a varias medidas del Pacto de Estado contra la Violencia de Género (2017).

${ }^{31}$ El mayor porcentaje de denuncias se registra para el robo del coche $(82,9 \%)$, según el Estudio CIS 2315

${ }^{32}$ La pregunta 12, del mismo estudio, exploraba las razones que en opinión de las personas entrevistadas llevarían a las victimas a no denunciar (el cuestionario contemplaba dos respuestas a) primera razón y b) segunda razón, que se analizan de forma agregada). Los resultados señalan que las principales razones para no comunicar los hechos a los cuerpos de seguridad fueron el 'miedo al agresor' (varones $72,7 \%$ y mujeres $73,1 \%$ ), seguido de 'la vergüenza' (varones $61,3 \%$ y mujeres $56,7 \%$ ), el 'miedo a que no la creyeran' (varones $23,4 \%$ y mujeres $29,8 \%$ ) y el el 'miedo a ser considerada culpable de lo sucedido' (varones $13,8 \%$ y mujeres $17,0 \%$ ). De estos resultados se deduce que las mujeres creen, en mayor medida, que las víctimas de violencia sexual son 'sospechosas' de lo ocurrido. 
Tabla 5: Opinión sobre la propensión a denunciar agresiones sexuales

\begin{tabular}{|l|c|c|c|}
\hline \multicolumn{1}{|c|}{ Categorías de respuesta (P.10) } & $\begin{array}{c}\text { Total } \\
\%\end{array}$ & $\begin{array}{c}\text { Mujeres } \\
\%\end{array}$ & $\begin{array}{c}\text { Varones } \\
\%\end{array}$ \\
\hline Siempre que sucede & 1,5 & 0,8 & 2,3 \\
\hline En la mayor parte de las ocasiones & 22,8 & 21,1 & 24,7 \\
\hline En pocas ocasiones & 61,7 & 64,2 & 59,0 \\
\hline Casi nunca & 9,0 & 10,1 & 7,9 \\
\hline N.S./N.C. & 5,0 & 3,7 & 6,1 \\
\hline (N) & 2.465 & 1.269 & 1.196 \\
\hline
\end{tabular}

Estudio CIS núm. 3182

En España existe un inexplicable vacío en la realización de encuestas de victimización de alcance nacional (Díez y García 2009: 33-35; Aebi y Linde 2010: 245-248). A diferencia de EEUU donde la National Crime Victimization Survey (NCVS), se realiza de forma ininterrumpida desde 1973, con periodicidad anual, o de Gran Bretaña que, desde 1982, cuenta con The Crime Survey for England and Wales (CSEW) ${ }^{33}$. En Francia l'Enquête victimation - Cadre de Vie et Sécurité (CVS), se realiza de forma continua desde 1996. Y, curiosamente, Cataluña es la única Comunidad Autónoma con una larga tradición en la realización periódica de encuestas de victimización. La actual Encuesta de Seguridad Pública de Cataluña (ESPC) se aplica de forma continua desde hace quince años y tiene su antecedente en la Encuesta de Victimización y opinión sobre la seguridad de Barcelona (EVB) del año 1984 (Murrià 2010: 67-68).

En perspectiva global, las encuestas de victimización realizadas a toda la población española han sido encargos específicos de escasa periodicidad. En la tabla 6 se identifican una serie de encuestas, de ámbito nacional, realizadas por el Centro de Investigaciones Sociológicas (CIS), en las últimas cuatro décadas (1978 y 2019) que incluyen preguntas directas para estimar el grado de victimización de la población y donde puede comprobarse la precocidad en el interés por la investigación criminológica que, en sólo dos años (1978, 1980), administró cuatro cuestionarios para examinar el grado de victimización de la población, de ambos sexos, mayor de 18 años y, a partir de entonces, sin saber por qué, las EV se han realizado de forma esporádica.

${ }^{33}$ Hasta el año 2009, esta encuesta se denominó British Crime Survey 
Tabla 6: Encuestas de Victimización de ámbito nacional realizadas por el CIS.

\begin{tabular}{|c|c|c|c|c|}
\hline$A \tilde{n} o$ & $\begin{array}{c}\text { Denominación de la } \\
\text { Encuesta }\end{array}$ & $\begin{array}{l}\text { Referen- } \\
\quad \text { cia }\end{array}$ & Universo & $\begin{array}{l}\text { Tamaño } \\
\text { muestral }\end{array}$ \\
\hline $\begin{array}{l}1978 \mathrm{a} \\
\text { Enero }\end{array}$ & Criminalidad & 1149 & $\begin{array}{c}\text { Pob. española / } \\
\text { ambos sexos / } 18 \text { y } \\
\text { más años }\end{array}$ & 1204 \\
\hline $\begin{array}{l}\text { 1978b } \\
\text { Mayo }\end{array}$ & Victimización & 1152 & $\begin{array}{c}\text { Pob. española / } \\
\text { ambos sexos / } 18 \text { y } \\
\text { más años }\end{array}$ & 5708 \\
\hline $\begin{array}{l}1980 a \\
\text { Enero }\end{array}$ & $\begin{array}{l}\text { Victimización y Dro- } \\
\text { ga }\end{array}$ & 1206 & $\begin{array}{c}\text { Pob. española / } \\
\text { ambos sexos / } 18 \text { y } \\
\text { más años }\end{array}$ & 6032 \\
\hline $\begin{array}{l}1980 \mathrm{~b} \\
\text { Noviem }\end{array}$ & $\begin{array}{l}\text { Inseguridad Ciudada- } \\
\text { na (I) } \\
\text { Sólo examina el delito } \\
\text { de robo }\end{array}$ & 1251 & $\begin{array}{l}\text { Pob. española / } \\
\text { ambos sexos / } 16 \text { y } \\
\text { más años }\end{array}$ & 1156 \\
\hline $\begin{array}{l}1991 \\
\text { Julio }\end{array}$ & $\begin{array}{l}\text { Inseguridad Ciuda- } \\
\text { dana }\end{array}$ & 1974 & $\begin{array}{c}\text { Pob. española / } \\
\text { ambos sexos / } 18 \text { y } \\
\text { más años }\end{array}$ & 2490 \\
\hline $\begin{array}{l}1995 \\
\text { Abril }\end{array}$ & $\begin{array}{l}\text { Delincuencia, Segu- } \\
\text { ridad Ciudadana e } \\
\text { Imagen de la Policía }\end{array}$ & 2152 & $\begin{array}{c}\text { Pob. española / } \\
\text { ambos sexos / } 18 \text { y } \\
\text { más años }\end{array}$ & 3919 \\
\hline $\begin{array}{l}1995 \\
\text { Dic }\end{array}$ & $\begin{array}{l}\text { Demanda de Seguri- } \\
\text { dad y Victimización }\end{array}$ & 2200 & $\begin{array}{l}\text { Pob. española / } \\
\text { ambos sexos / } 18 \text { y } \\
\text { más años }\end{array}$ & $\begin{array}{c}14994 \\
17 \text { muestras } \\
\text { provinciales } \\
\text { independien- } \\
\text { tes }\end{array}$ \\
\hline $\begin{array}{l}1998 \\
\text { Abril }\end{array}$ & $\begin{array}{c}\text { Seguridad Ciudadana } \\
\text { y Victimización (I) } \\
\text { Encargo DG de G. } \\
\text { Civil }\end{array}$ & 2284 & $\begin{array}{c}\text { Pob. española / } \\
\text { ambos sexos / } 18 \text { y } \\
\text { más años residente } \\
\text { en municipios de } \\
\text { tamaño igual o } \\
\text { inferior a 50.000 } \\
\text { habitantes }\end{array}$ & $\begin{array}{c}2456 \\
\text { Excluye el } \\
\text { territorio de } \\
\text { Euskadi }\end{array}$ \\
\hline $\begin{array}{l}1999 \\
\text { Enero }\end{array}$ & $\begin{array}{l}\text { Seguridad Ciudadana } \\
\text { y Victimización (II) }\end{array}$ & 2315 & $\begin{array}{l}\text { Pob. española / } \\
\text { ambos sexos / } 18 \text { y } \\
\text { más años }\end{array}$ & $\begin{array}{c}12994 \\
17 \text { muestras } \\
\text { autonómicas } \\
\text { independien- } \\
\text { tes }\end{array}$ \\
\hline $\begin{array}{l}\text { 2015-16 } \\
\text { dic-abril }\end{array}$ & $\begin{array}{c}\text { Encuesta Social } \\
\text { General Española } \\
\text { (ESGE) }\end{array}$ & 3123 & $\begin{array}{c}\text { Residentes / ambos } \\
\text { sexos / } 18 \text { y más } \\
\text { años }\end{array}$ & 5290 \\
\hline $\begin{array}{l}2019 \\
\text { Julio }\end{array}$ & Barómetro CIS & 3257 & $\begin{array}{c}\text { Pob. española / } \\
\text { ambos sexos / } 18 \text { y } \\
\text { más años }\end{array}$ & 2952 \\
\hline
\end{tabular}

Fuente: Banco de Datos CIS. Elaboración propia

Una Encuesta de Victimización, propiamente dicha, implica diseñar preguntas orientadas a estimar el alcance de la victimización en un territorio y demanda 
información amplia en tres aspectos: a) si se ha sufrido algún delito o intento (a lo largo de la vida o en un período de tiempo determinado -en últimos 5, 10 años o, en el último año-), b) en caso de que la respuesta sea afirmativa se solicita a la persona entrevistada que indique de cuál o cuáles delitos fue víctima, aplicando una batería específica de cuestiones a indagar para cada tipología penal y c) si denunció, o no, los hechos y qué razones le llevaron a declarar ante los cuerpos policiales u omitir la comunicación. Por tanto, es importante señalar que no todas las encuestas que incluyen preguntas sobre victimización y seguridad puedan considerarse como $\mathrm{EV}^{34}$.

La información compilada muestra que en el transcurso de cuatro décadas se han realizado diez encuestas que, con calidades diferenciadas, pueden considerarse Encuestas de Victimización (Tabla 6).

A estos estudios de ámbito nacional hay que añadir otros estudios, también realizados por el CIS pero con carácter territorial (Tabla 7).

Tabla 7: Encuestas de Victimización de ámbito territorial realizadas por el CIS.

\begin{tabular}{|c|c|c|c|c|}
\hline$A \tilde{n} o$ & $\begin{array}{c}\text { Denominación de la } \\
\text { Encuesta }\end{array}$ & $\begin{array}{l}\text { Referen- } \\
\quad \text { cia }\end{array}$ & Universo & $\begin{array}{l}\text { Tamaño } \\
\text { muestral }\end{array}$ \\
\hline $\begin{array}{l}1982 \\
\text { Mayo }\end{array}$ & $\begin{array}{l}\text { Estudio sobre inseguri- } \\
\text { dad ciudadana (II) }\end{array}$ & 1313 & $\begin{array}{l}\text { Pob. ambos sexos } \\
\text { / mayor de } 15 \text { años } \\
\text { residente en los ayun- } \\
\text { tamientos de Madrid, } \\
\text { Málaga y Zamora }\end{array}$ & 2.364 \\
\hline 1995 & $\begin{array}{c}\text { Delincuencia, Segu- } \\
\text { ridad e imagen de la } \\
\text { Policía }\end{array}$ & 2152 & $\begin{array}{c}\text { Muestras independien- } \\
\text { tes de los ayuntamien- } \\
\text { tos y áreas metropo- } \\
\text { litanas de Barcelona, } \\
\text { Bilbao, Madrid, Sevi- } \\
\text { lla y Valencia }\end{array}$ & \\
\hline $\begin{array}{l}2007 \\
\text { Junio }\end{array}$ & $\begin{array}{l}\text { Delincuencia y victimi- } \\
\text { zación en la CAM }\end{array}$ & 2702 & $\begin{array}{c}\text { Pob. residente / ambos } \\
\text { sexos / } 16 \text { y más años } \\
\text { CAM }\end{array}$ & 1.501 \\
\hline
\end{tabular}

Existen, asimismo, algunos barómetros que incluyen un módulo específico, bien para estimar de forma agregada si se ha sido víctima de 'cualquier' delito o, intento de delito (Estudios CIS 1453 y 2364) ${ }^{35}$; bien para describir la probabilidad de ser víctima de un delito en el barrio de residencia de la persona encuestada (Estudios CIS 2528 y 2888) ${ }^{36}$. Y, por último, conviene apuntar que existen a nivel nacional dos estudios monográficos sobre delincuencia sexual, uno la Encuesta sobre Acoso Sexual (Estudio CIS núm. 2422) realizado en el año 2001

34 Josu Gondra (2008: 97) identificó un conjunto mayor de estudios pero, en nuestra opinión, una parte importante no pueden considerarse EV pues, en muchos casos, sólo estiman de forma agregada la incidencia de 'cualquier' delito en el conjunto de la población española.

${ }_{35}$ Estudio 1453 (Barómetro marzo 1985); Estudio 2364 (Barómetro junio 1999).

${ }^{36}$ Estudio 2528 (Barómetro junio 2003); Estudio 2888 (Barómetro mayo 2011). 
y, otro la Encuesta sobre Percepción de la Violencia Sexual aplicada en el año 2017 (Estudio CIS núm. 3182). Además, a nivel autonómico se debe considerar las dos ediciones de la Enquesta de violència masclista a Catalunya (2010 y 2016), parcialmente analizada por Igareda y Bodelón (2014).

A nivel municipal contamos con la Encuesta de victimización en el área metropolitana de Barcelona, que se realiza con periodicidad anual desde el año 1985 por el Institut d'Estadística de Catalunya y, a nivel autonómico, son valiosas la EV elaboradas por el Instituto Andaluz Interuniversitario de Criminología en el ayuntamiento de Málaga (2006), los municipios de Córdoba, Huelva y Sevilla (2007), las capitales andaluzas (2008) y áreas urbanas (capitales españolas y municipios de más de 50.000 habitantes en 2009).

En perspectiva internacional, otra interesante fuente de información especializada para el estudio de las violencias sexuales se tiene en la International Crime Victims Survey - ICVS. España participó en la Encuesta Internacional de Victimización en 1989 y $2005^{37}$. El cuestionario de la ICVS interroga sobre una serie de delitos habituales, incluyendo las agresiones sexuales ${ }^{38}$. La encuesta identifica a las víctimas de este tipo delictivo con la siguiente pregunta: P. 80 Comencemos, con una pregunta muy personal. En ocasiones, algunas personas cogen, tocan o atacan a otras por motivos sexuales, de una manera realmente ofensiva. Esto puede suceder en la vivienda o en cualquier otro lugar, por ejemplo, en un pub, la calle, la escuela, el transporte público, el cine, la playa o en el centro de trabajo. En los últimos cinco años, ¿alguien le ha hecho esto? Por favor tómate tu tiempo para pensarlo. El contenido específico sobre violencias sexuales aborda la diversidad de estas en forma de acoso, tocamiento, abuso y agresión; examinando a) el territorio donde se produjo el delito (dentro o fuera del país de residencia) y b) el lugar de la comisión delictiva (vivienda, escuela, centro de trabajo, transporte, vía pública o lugares de ocio y esparcimiento como bares, cines o playa). El cuestionario también contempla preguntas sobre el vínculo entre víctima y agresor y, el número de victimarios implicados en el delito, así como la percepción que para la víctima tuvo el incidente (grave, muy grave, sin importancia). Por último, se pregunta si la víctima denunció los hechos y, en caso negativo, por qué no lo comunicó a la policía.

A modo de síntesis, son muchas la investigaciones empíricas y epistemológicas que reconocen el valor de las Encuestas de Victimización como la mejor es-

37 La Encuesta Internacional de Victimización (International Crime Victims Survey - ICVS) es un ambicioso proyecto iniciado en 1987 por un grupo de criminólogos europeos con experiencia en encuestas de victimización de ámbito nacional (Van Dijk, Mayhew, Killias 1990). Hasta el momento ha realizado cinco rondas de aplicación en 1989 (con la participación de 14 países); 1992 (33 países); 1996 (48 países); 2000 (48 países, participa Barcelona); 2004-2005 (30 países y 33 ciudades). Entre los años 2010 y 2015 se promovió una última edición pero con muy baja participación. Toda la información estratégica sobre este proyecto puede consultarse en una sección específica de la website del Instituto de Criminología y Derecho Penal de la Universidad de Lausanne (Suiza) https://wp.unil.ch/icvs/

38 Una versión traducida del cuestionario se puede consultar en Díez y García (2009: 173205), la sección específica sobre agresiones sexuales se localiza en las páginas 191-194. 
trategia metodológica para monitorizar el alcance de la criminalidad, la percepción sobre la inseguridad y la opinión de la ciudadanía sobre el funcionamiento de instituciones policiales y judiciales. Y sin embargo, España mantiene un déficit inaceptable en la aplicación de esta técnica de investigación social. Este aspecto, interpela a las instituciones competentes a abordar, de manera urgente, la elaboración de encuestas de victimización en España, como una operación estadística permanente al servicio de los cuerpos de seguridad del Estado y de la ciudadanía del país.

\subsection{Otras fuentes para el estudio de las violencias sexuales}

En noviembre de 2018, el Gabinete de Coordinación y Estudios de la Secretaria de Estado de Seguridad (GCESES) publicaba una monografía sobre criminalidad sexual en España, en el que se reconoce un aumento significativo de esta tipología delictiva, en el último lustro. Esta tendencia de claro crecimiento de la delincuencia sexual registrada, en un contexto de descenso de la criminalidad general, también ha sido advertida en las cifras compiladas por la Oficina Europea de Estadística que indica un aumento del 26 por ciento de esta tipología penal entre los años 2013 y 2016 (Eurostat, 2018). Análogo diagnóstico declaró el jefe de policía James O'Neill para la ciudad de Nueva York: -“Crime is down in NYC, but rape is a glaring exception", afirmando en rueda de prensa que las denuncias por violación aumentaron un 24,4 por ciento en el año 2018, con respecto a $2017^{39}$. Y más recientemente, el 9 de septiembre de 2019, con motivo de la inauguración del año judicial, la fiscal general M. ${ }^{a}$ José Segarra, exponía algunos de los aspectos más relevantes de la Memoria Anual de la Fiscalía General del Estado (2018), señalando el aumento de los delitos sexuales juzgados en España. Estas consistentes informaciones apuntan a que la violencia sexual es un fenómeno grave, de progresiva y creciente visibilización y, lo que es más preocupante que no se está traduciendo en el diseño de políticas públicas para su intervención, erradicación y reparación.

La monografía aludida y titulada Informe sobre delitos contra la libertad e indemnidad sexual en España es una publicación innovadora y motivada: "por el reproche social y penal que merecen la comisión de estas formas delictivas, especialmente agravado en el caso de las formas más violentas, así como las ejercidas sobre víctimas vulnerables, unido al incremento delincuencial experimentado en los últimos años" (GCESES 2018:1).

El informe aporta datos no recogidos por los Anuarios MIR, como por ejemplo, a) la estacionalidad de la delincuencia sexual que informa de la distribución mensual de delitos registrados, confirmándose un aumento significativo en los meses de mayo a septiembre, b) la plena desagregación de las tipologías penales (11 categorías de clasificación frente a las 4 del Anuario MIR) y donde se ad-

${ }^{39}$ Website NY Public Radio 3 de enero de 2019, disponible en la siguiente dirección URL https://www.wnyc.org/story/crime-down-nyc-rape-glaring-exception/ 
vierte de forma contundente que el $75 \%$ de los hechos conocidos están referidos a los subtipos más graves: abuso y agresión sexual, c) la indicación de los lugares de la comisión de delitos sexuales, por la que se indica que el $40 \%$ de las denuncias de violencia sexual se producen en viviendas, otro $42 \%$ en espacios públicos, incluidos los medios de transporte y el resto en categorías genéricas como 'establecimientos' (8\%) e 'instalaciones y recintos' (8\%).

Este informe también explora de forma laxa a victimarios (investigados), ofreciendo una distribución de investigados por subtipo penal, pero nada refiere de sus características sociodemográficas. Análogas particularidades se reflejan en la sección de 'victimizaciones', donde el dato más relevante es la confirmación del aumento de víctimas menores de edad y la preferencia de los victimarios por mujeres jóvenes.

Esta publicación representa un avance interesante pero sigue mostrando deficiencias inexplicables, como por ejemplo que las cifras suministradas refieran datos absolutos y no tasas, cuestión que como ya se señaló impide realizar comparaciones interespaciales e intertemporales. El informe tampoco ofrece datos sobre las agresiones sexuales en grupo, cuando sabemos que ya la pornografía ha creado un género denominado 'violación la manada' ${ }^{40}$.

Otra iniciativa reseñable es el proyecto Geoviolencia Sexual emprendido por el colectivo Feminicidio.net, en el año 2016, tras conocerse el caso 'San Fermín', por el que se decidió poner en marcha una investigación hemerográfica que permitiera contextualizar la violación en España y se empezó a contabilizar agresiones sexuales en grupo (participación de dos o más victimarios), a partir del monitoreo de noticias publicadas por medios de comunicación digital en España. Esta acción activista tiene indudables límites, como por ejemplo, no poder hacer como un registro completo del suceso, pues sólo tiene en cuenta los casos dados a conocer en la mediasfera y que, con mucha probabilidad, son una parte muy pequeña de las violaciones en grupo pero, lo más valioso, en nuestra opinión, es que pone al descubierto la deficiencia de los datos oficiales y la exigencia de destinar recursos para crear un Observatorio, con recursos especializados que permita estimar, estudiar y, posteriormente intervenir sobre este problema social de interés general. La iniciativa de Feminicidio.net recuerda los registros emprendidos por la Federación de Mujeres Separadas y Divorciadas, a mediados de los años noventa del siglo XX para visibilizar la gravedad de la violencia de género y su escasa e incompleta cuantificación. La Federación desarrolló una

40 Esta nueva oferta no representa, en sentido estricto, una innovación ya que en los géneros de producción pornográfica se pueden encontrar desde hace décadas el género 'Gang Bang' o la 'Orgía'. En este sentido y sin querer simplificar la complejidad del tema, queremos hacer referencia al reciente estudio de Ballester y Orte (2019), 'Nueva pornografía y cambios en las relaciones interpersonales', donde a partir de una encuesta de ámbito cuasi nacional $(n=2.457)$, dirigida a jóvenes de entre 16 y 29 años, se revela que la edad promedio de inicio en el consumo de pornografía son los 14 años entre los adolescentes varones, y de 16 años en el caso de las mujeres. Lo más relevante, en nuestra opinión, es la posibilidad de adicción a la pornografía para el desarrollo de prácticas de autoerotismo, además de la persistencia de hegemonía sexista en los contenidos de pornografía gratuita online que cosifican y violentan el cuerpo de las mujeres. 
similar metodología "la recopilación de datos sobre la violencia de pareja con resultado de muerte haciendo un seguimiento sistemático de la prensa diaria" (Osborne 2008: 104). El proyecto Geoviolencia Sexual nos ha hecho tomar conciencia de que este tipo de delitos no son un caso aislado y, desde que se iniciara el registro, se han contabilizado 211 agresiones sexuales múltiples en España ${ }^{41}$, por lo que las administraciones publicas de carácter nacional, autonómico y municipal deben atender e intervenir la violencia sexual, por su magnitud y por los daños traumáticos causados a las víctimas.

\section{LOS DELITOS CONTRA LA LIBERTAD SEXUAL EN EL CONTEXTO DE LA CRIMINALIDAD EN ESPAÑA}

En esta sección facilitamos las cifras consignadas en los Anuarios MIR sobre los delitos denunciados contra la libertad sexual entre 1989 y 2018, así como la evolución de la infracción que con mayor rigor sanciona el Código Penal, la agresión sexual con penetración, identificada popularmente como 'violación'.

\subsection{De la violencia sexual a las cifras de delincuencia sexual}

El último dato publicado por el Ministerio del Interior sobre el registro de delitos 'Contra la libertad sexual' señala que en el año 2018 se conocieron 13.782 denuncias $^{42}$, una cifra que, no ha dejado de aumentar desde el inicio de la serie. Si consideramos la evolución desde el año en el que centralizaron las estadísticas de seguridad, el crecimiento es muy significativo, por cada 100 denuncias por delitos contra la libertad sexual en 2012, se registraron 153 en 2018, una tendencia preocupante. Por otro lado, creemos que, para poder interpretar adecuadamente esta cifra, debemos examinarla en el contexto de la criminalidad general en España.

En materia de 'Seguridad Ciudadana', los Anuarios MIR ofrecen una síntesis sobre la incidencia del delito en grandes agregados, de la cual se deduce una indiscutible concentración de denuncias en la categoría 'Contra el patrimonio' (78 \%) que acumula más de las tres cuartas partes de la criminalidad conocida por los cuerpos de seguridad ${ }^{43}$, seguida de la rúbrica 'Contra las personas y la libertad' $(15 \%)^{44}$, monitorización que se completa con la clasificación 'Otras

${ }^{41}$ La distribución de agresiones múltiples fue la siguiente: 18 en 2016, 14 en 2017, 60 en 2018 y 86 en 2019 y 27 en 2020. La website de Geoviolencia Sexual puede consultarse en la siguiente dirección URL https://geoviolenciasexual.com/

${ }^{42}$ Anuario Estadístico MIR 2018, pág. 161.

${ }^{43}$ Incluye las infracciones de hurtos $(34,8 \%)$, robos $(17,7 \%)$, daños $(10,5 \%)$ y otros delitos contra el patrimonio $(14,8 \%)$.

${ }^{44}$ Incluye las infraciones de homicidios $(0,38 \%)$, asesinatos $(0,10 \%)$, lesiones $(34,19 \%)$, malos tratos en el ámbito familiar $(23,78 \%)$, malos tratos habituales en el ámbito familiar $(4,85$ $\%)$ y otros delitos contra las personas y la libertad $(36,70 \%)$. 
infracciones penales' $(7 \%)$. Esta primera radiografía revela que el principal delito registrado está relacionado con hurtos, robos y daños diversos a la propiedad, hecho que se traduce en una percepción de inseguridad muy baja entre la ciudadanía española ${ }^{45}$.

Los Anuarios también proporcionan un esquema marco de la distribución de las principales infracciones penales en 12 epígrafes y 36 categorías (Аnиаrio MIR, 2018: 161). A efectos de pragmatismo y dada la preeminencia de los delitos 'Contra el patrimonio' (78 \% del total de la criminalidad), si queremos valorar la importancia de los delitos denunciados 'Contra la libertad sexual', tiene sentido excluir de la comparación la tipología penal 'contra el patrimonio' y, así, cotejar con más matices cómo se distribuye la criminalidad en España. En la tabla 8, se aprecia, con mayor claridad la jerarquía de los delitos según sus magnitudes relativas, expresadas como porcentaje.

Tabla 8: Distribución de las infracciones penales (2018).

\begin{tabular}{|l|r|r|r|r|}
\hline \multicolumn{1}{|c|}{ Infracciones Penales } & $\begin{array}{c}\text { Hechos co- } \\
\text { nocidos }\end{array}$ & \multicolumn{1}{c|}{$\%$} & $\begin{array}{c}\text { Estimación de } \\
\text { la criminalidad } \\
\text { sexual }\end{array}$ & \multicolumn{1}{c|}{$\%$} \\
\hline I. Contra las personas & 177.165 & 8,31 & 177.165 & 33,94 \\
\hline II. Contra la libertad & 120.919 & 5,67 & 120.919 & 23,16 \\
\hline III. Contra la libertad sexual & 13.782 & 0,65 & $68.910 *$ & 13,20 \\
\hline IV. Relaciones Familiares & 7.630 & 0,36 & 7.630 & 1,46 \\
\hline V. Contra el patrimonio & 1.664 .242 & 78,09 & & \\
\hline VI. Seguridad Colectiva & 64.126 & 3,01 & 64.126 & 12,28 \\
\hline VII. Falsedades & 22.399 & 1,05 & 22.399 & 4,29 \\
\hline VIII. Admón. Pública & 510 & 0,02 & 510 & 0,10 \\
\hline IX. Admón. Justicia & 30.290 & 1,42 & 30.290 & 5,80 \\
\hline X. Orden Público & 20.121 & 0,94 & 20.121 & 3,85 \\
\hline \multicolumn{1}{|c|}{ XI. Legislación Especial } & 209 & 0,01 & 209 & 0,04 \\
\hline XII. Otras infracciones & 9.725 & 0,46 & 9.725 & 1,86 \\
\hline TOTAL & $\mathbf{2 . 1 3 1 . 1 1 8}$ & $\mathbf{1 0 0 , 0 0}$ & & \\
\hline
\end{tabular}

* Estimación de la criminalidad sexual (Hechos conocidos por 5)

Fuente: Anuario Estadístico del Ministerio del Interior (2018: 161)

${ }^{45}$ Los Barómetros del CIS incluyen, desde octubre de 1997, dos preguntas de respuesta abierta y múltiple sobre los tres principales problemas del país: “¿Cuál es, a su juicio, el principal problema que existe actualamente en España?” у “Cuál es el problema que a Ud., personalmente, le afecta más?". La evolución de las series temporales sobre las respuestas a estas preguntas permiten afirmar que, en la actualidad menos del 5 por ciento de la población española considera la 'inseguridad' un problema social, Soto (2005: 104-110) y Caro y Navarro (2017: 32-37). 
Según esta información la delincuencia sexual parece tener una incidencia muy pequeña en el conjunto de la criminalidad del país, (Tabla 8, porcentaje 'Hechos Conocidos' 0,65 \%), ocupando el séptimo lugar, en la distribución de magnitudes. No obstante, es necesario incidir en que estas cifras no reflejan la violencia sexual, sino que expresan las denuncias presentadas. Si como vimos en un epígrafe anterior, la delincuencia sexual es una de las figuras delictivas menos denunciadas, como reconoce la propia policía (Martín Parra 2006: 17) y, teniendo en cuenta los hallazgos de diversos estudios empíricos especializados ya citados que estiman que, en promedio, sólo se denuncia ante la policía un 20 por ciento de las violencias sexuales, la cifra de delitos registrados "contra la libertad sexual' debería ser multiplicada por 5; teniendo en cuenta ese criterio, si se realiza una estimación en la magnitud de los delitos 'Contra la libertad sexual', para corregir el efecto de inhibición de las víctimas y, admitiendo que se trata de un ejercicio especulativo, el resultado nos indicaría que esta tipología delictiva se convierte en la tercera infracción penal en España -excluidos los delitos 'Contra el patrimonio'. Con este ajuste, especulativo pero verosímil, se quiere enfatizar que las violencias sexuales son un fenómeno estadísticamente significativo para el que no existen, como ya se ha señalado con anterioridad, políticas públicas orientadas a su prevención (Amnistía Internacional 2018: 6 y 12-17). Por el contrario, existen otros fenómenos de interés social a los que se destinan importantes partidas presupuestarias para reducir su incidencia. Así, por ejemplo, las víctimas mortales por accidentes de tráfico no han cesado de descender desde 1989, en parte, como efecto de las políticas públicas de prevención y sanción. En este caso, la sociedad española tiene conciencia del riesgo merced a las campañas de sensibilización difundidas por la DGT y también se percibe la peligrosidad de conducir incumpliendo las 'reglas' (velocidad, consumo de sustancias o uso de dispositivos móviles) y aunque los efectos de las políticas públicas no han conseguido erradicar los siniestros mortales en carreteras, sí han hecho descender los números de forma sensible. En otras palabras, la importante y creciente incidencia de la criminalidad sexual registrada exige que de manera urgente se diseñen e implementen políticas públicas para su prevención y reparación.

\subsection{Evolución de los delitos contra la libertad sexual, 1989-2018}

Conocer la evolución de los delitos registrados contra la libertad sexual en las tres últimas décadas no es un ejercicio sencillo pues como ya se mencionó, sólo disponemos de estadísticas centralizadas sobre criminalidad desde el año 2012. En años anteriores, la reconstrucción de una serie completa para el país implicaría consultar los Anuarios estadísticos de las policías autonómicas de Cataluña, Navarra y País Vasco. Este sub-registro es técnicamente subsanable, si hubiera voluntad y conciencia de rectificar las omisiones, puesto que un país con el nivel de desarrollo de España no puede tener en este ámbito de actuaciones, una fuente tan defectuosa. 
El gráfico 1 representa la evolución de las cifras publicadas por los Anuarios MIR, siendo por tanto una serie incompleta entre 1989 y 2011. Lo más llamativo es la tendencia ascendente de la serie, especialmente en los cinco últimos años y que, volvemos a repetirlo, es una indicación elocuente de la importancia de este suceso.

En la gráfica se observa que el nivel más bajo de delito registrado se localiza en 1990 y va aumentando con ritmos de diversa intensidad. Entre 1998 y 2006 el Anuario Estadístico comunica los delitos conocidos por el Cuerpo Nacional de Policía (CNP) y la Guardia Civil (GC), pero también consigna, de manera separada, la información disponible de la Policía Autónoma Vasca (PAV) ${ }^{46}$. En el gráfico hemos creado distintas tramas para rectificar la serie (1998-2006), pero conviene insistir en que esta estadística sigue siendo incompleta, hasta el año 2012, al no estar incluidas las cifras de Cataluña y Navarra (Aebi y Linde, 2010: 4).

\section{Gráfico 1: Evolución de los delitos denunciados contra la libertad sexual, 1989- 2018 (Hechos conocidos) $^{47}$}

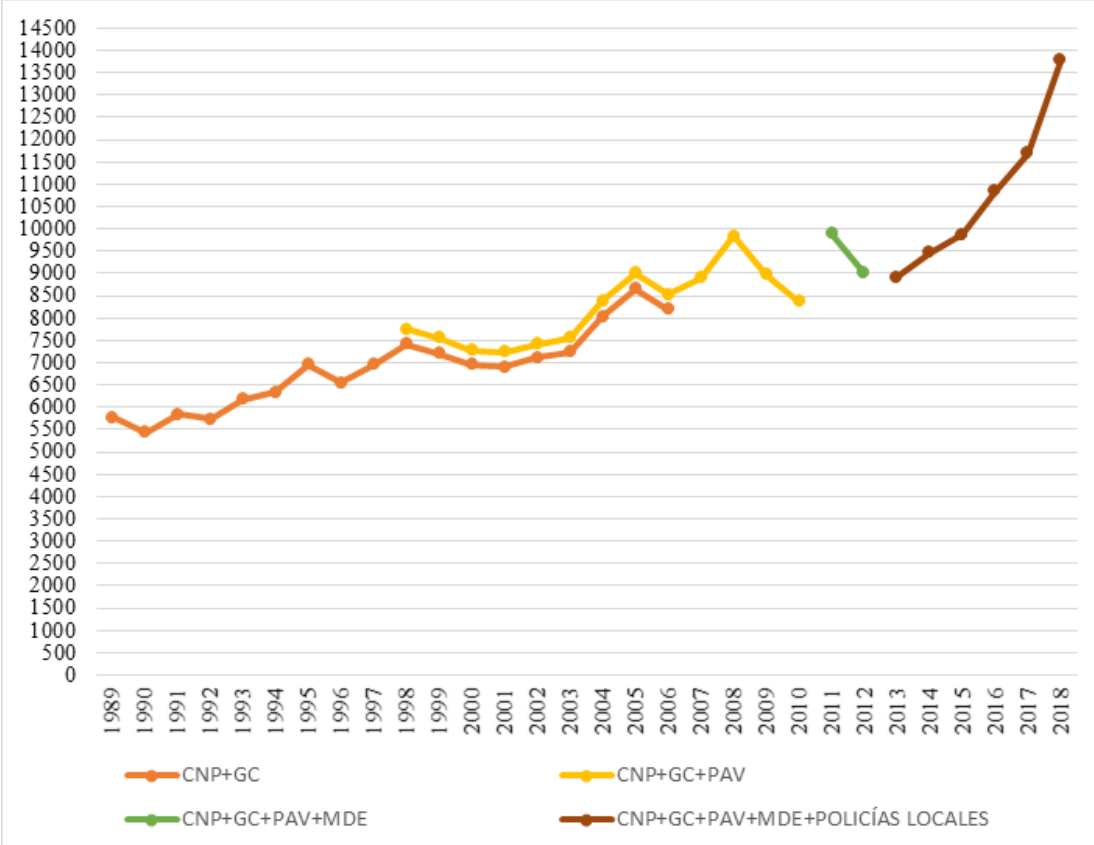

${ }^{46}$ En la reconstrucción de la serie que aquí se presenta, mediante la consulta de los Anuarios MIR, se han detectado diversos errores, por ejemplo, el gráfico 31 del Anuario 2005 contiene errores en la suma de las magnitudes, el documento señala que el volumen de delitos denunciados asciende a 8.657 (Anuario MIR 2005: 230, grafico 31); sin embargo, omite los 354 registros de la PAV, cuyo sumatorio nos daría la cifra de 9.011 denuncias (Anuario MIR 2005: 304).

47 CNP: Cuerpo nacional de policía; GC: Guardia Civil; PAV: Policía Autonómica Vasca; MDE: Mossos d'Esquadra. 
Otra cuestión interesante es advertir la estacionalidad en la evolución de las denuncias de violencia sexual (GCE-SES 2018: 3). La distribución mensual del registro (Gráfico 2) permite afirmar que existe un aumento de estas infracciones en los meses de mayo a septiembre, es decir, en las estaciones de primavera y verano. La hipótesis que barajamos es que este incremento guarda relación con que, en el período de vacaciones las jóvenes (principales víctimas de la violencia sexual) salen más y la benignidad de la temperatura favorece prolongar la movilidad nocturna, sin olvidar que en esta época se organizan toda una serie de festivales, fiestas populares y viajes vacacionales, circunstancias que serían aprovechadas por los agresores para asaltar sexualmente a las víctimas.

\section{Gráfico 2: Evolución del total los delitos denunciados contra la libertad sexual, 1995-2006 (Hechos conocidos, distribución mensual).}

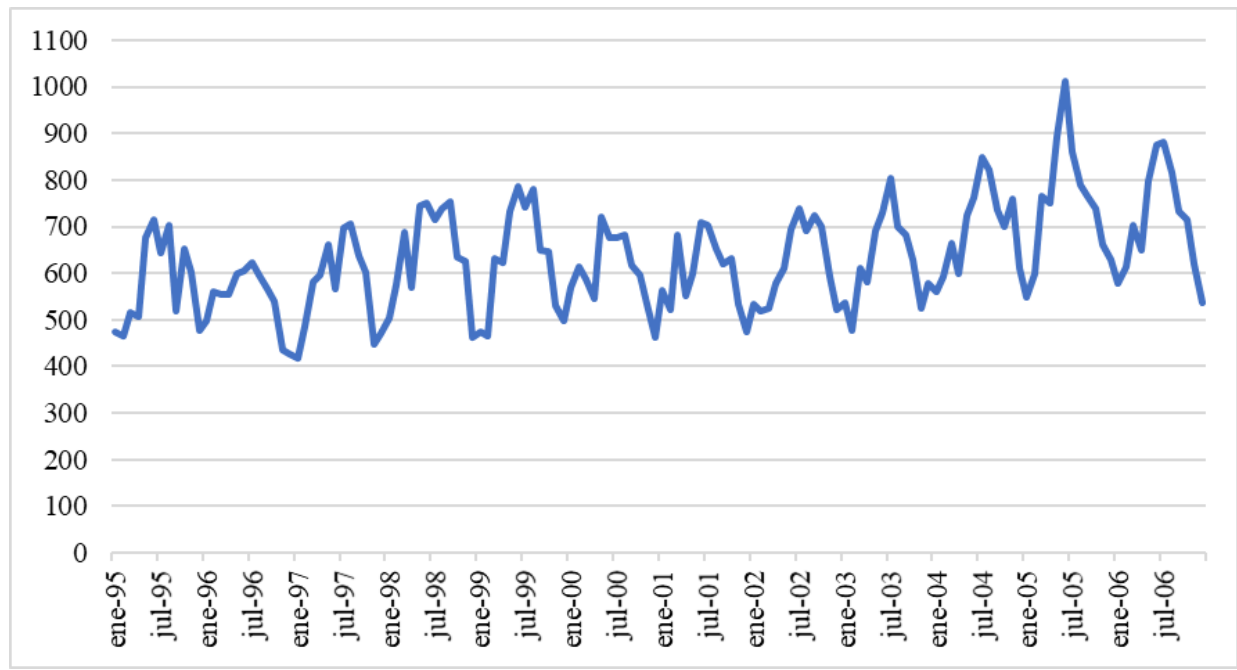

Fuente: Anuario Estadístico MIR (varios años). Elaboración propia

\subsection{El delito de violación, 1989-2018}

El ordenamiento penal de la criminalidad sexual establece una jerarquía sancionadora cuyo límite superior es la agresión sexual: "cuando consista en acceso carnal por vía vaginal, anal o bucal...será castigado como reo de violación" (art. 179) pero esta calificación se establecerá si el delito, o su tentativa, se produjo mediante el uso de violencia o intimidación ${ }^{48}$. La evolución de la estadística

48 Existe una gran debate jurídico y ciudadano sobre la redacción e interpretación de algunos artículos del Código Penal, pues si el bien jurídico protegido es la libertad, su vulneración debería examinar si hubo o no consentimiento, en vez de centrarse en la presencia de violencia física/ 
de violaciones registradas, publicadas en los Anuarios MIR (Gráfico 3), teniendo en cuenta que hasta el año 2011 excluye las denuncias de Cataluña, Navarra y Euskadi, muestra una tendencia descendente con la presencia de aumentos puntuales en los años 1991, 1995, 2002, 2005, 2007, 2011, 2017 y 2018. Esta trayectoria nos parece poco consistente, si tenemos en cuenta que la criminalidad sexual está aumentando en España y en Europa (Eurostat, 2018 'police-recorded offences/sexual offences'). La serie parece difícil de interpretar por si misma y creemos que habría que comprobar si los años en los que se registran incrementos puntuales guardan relación con procesos de mayor intolerancia al delito, auspiciados por la visibilización mediática de violadores en serie. Asimismo, creemos que la serie puede estar también muy afectada por la secular actitud de 'silenciamiento' de las víctimas. Las mujeres, socializadas en el miedo, expresan que "una violación es lo peor que te puede pasar" (SORTZEN 2011: 41 y 559) y tenderían a ocultar los hechos por vergüenza, sentimiento de culpa y elusión del estigma social, pues como se deduce de la afirmación de Marta Murrià, la comunicación delictiva ante los cuerpos policiales puede estar afectada por la conciencia social del fenómeno y, en consecuencia, por la actitud cultural compartida de 'resignación' o intolerancia:

"la falta de motivación para interponer una denuncia puede provocar una disminución en los hechos registrados por los servicios policiales, y eso a pesar de que el número de personas que sufren estos delitos se haya visto incrementado. Y a la inversa, una buena predisposición de los ciudadanos para dar a conocer determinados hechos puede comportar un incremento en el número de denuncias registradas por los servicios de policía, sin que se haya producido un incremento real en el número de hechos que han sucedido" (Murrià, 2010: 69).

ambiental para calificar la violación como agresión sexual. En este sentido, el Tribunal Supremo (junio 2019) sobre los 'Hechos probados' de la violación de 'San Fermín 2016' recalificó el delito de abuso por el de agresión sexual, aumentando las penas de los victimarios y, sin embargo, en noviembre de 2019 la Audiencia Provincial de Navarra ha considerado la violación en grupo de cinco jóvenes a una menor como un delito de abuso sexual (La Manada de Manresa). 


\section{Gráfico 3: Evolución del delito de violación 1987-2018}

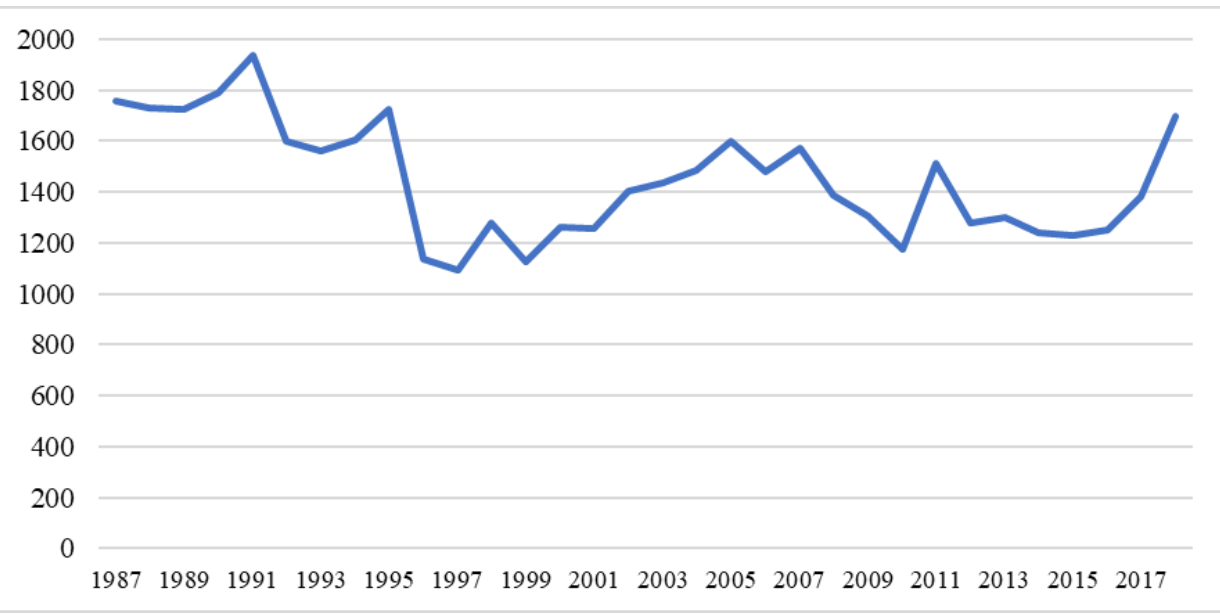

Fuente: Anuario Estadístico del Ministerio del Interior (varios años)

En ese sentido se comprende el énfasis que la joven violada, en las fiestas de San Fermín en 2016, dirigía a otras víctimas de agresión sexual. Esta joven escribió dos cartas a la ciudadanía española, remitidas para su difusión al programa de la periodista A.R. Quintana (27/06/2018 y 28/06/2019), en ellas, además de agradecer el apoyo recibido, exhortaba a otras víctimas a denunciar:

"Por favor, solo pido que por mucho que penséis que no os van a creer, denunciéis... Contadlo a un amigo, a un familiar, a la policía, en un tuit, hacedlo como queráis, pero contadlo. No os quedéis callados, porque si lo hacéis, les estáis dejando ganar a ellos" (27/06/2018); "Recordad contarlo, no les dejéis ganar a ellos" (28/06/2019).

La joven incorpora en la segunda oración el efecto del mandato de silencio que no es otro que la impunidad de los victimarios. Los agresores sexuales actúan con el convencimiento de que será difícil que las mujeres hagan público el delito, por vergüenza, sentimiento de culpa o miedo a la incomprensión. De modo que, las agresiones quedan, en su inmensa mayoría, en el limbo de lo inexistente, pues el silencio favorece la impunidad de los victimarios. Se podría afirmar que existe un circuito de reafirmación del silenciamiento, que traslada a la víctima la responsabilidad del abuso: porque ellas estaban 'en el lugar inadecuado', 'a una hora inadecuada', 'con ropa inadecuada', 'en compañía inadecuada', 'bebiendo de forma inadecuada' ... etc. De esta manera, se pretende inducir, y de forma secular se ha conseguido, que la víctima alimente un sentimiento de culpa y vergüenza.

La magnitud absoluta de denuncias por violación alcanza un promedio de 1.500 , en el período de observación. Una voluminosa cifra, si se tiene en cuenta que, por ejemplo, el promedio de víctimas mortales por violencia machista en 
los últimos cinco años es de 55 mujeres asesinadas. En términos relativos y en perspectiva comparada, por cada víctima mortal de violencia de género se denunciaron 27 violaciones y ello, sabiendo, que el registro de agresiones sexuales mantiene un significativo subregistro.

\section{4. (IN) CONCLUSIONES}

La criminalidad sexual en España no es un suceso marginal; el último dato oficial señala que en el año 2019 se registraron más de 15.000 denuncias (15.319) y, ello significa, en términos relativos, que cada tres horas se comunican ante los cuerpos de seguridad más de cinco delitos de esta naturaleza. Y pese a que conocemos el grave impacto físico, psicológico y emocional de esta forma de delincuencia en las víctimas, las administraciones públicas mantienen una incompresible desatención, por su inacción, ante esta forma de violencia de género (Amnistía Internacional, 2018)

En este artículo hemos examinado los organismos y fuentes disponibles para el estudio cuantitativo de la delincuencia sexual en España mostrando y concluyendo que las estadísticas disponibles presentan grandes limitaciones. Las estadísticas que difunde el Ministerio del Interior son imprecisas, entre otras cuestiones, por presentar una excesiva agregación en las categorías de clasificación, por publicar de forma habitual magnitudes absolutas, impidiendo la comparación interespacial e intertemporal y, sobre todo, por ofrecer un insuficiente número de variables que impide conocer cuestiones tan importantes como saber la relación entre víctima y agresor(es), la reiteración del delito, el contexto espacio-temporal de la violencia, la frecuencia de las agresiones sexuales en grupo o, una cuestión tan importante como conocer las características sociodemográficas de víctimas y victimarios. La evaluación de las estadísticas del delito denunciado interpela directamente al Ministerio del Interior para poner a disposición los recursos necesarios para mejorar la calidad de los datos, en todos los criterios examinados: disponibilidad y accesibilidad, claridad conceptual y variables de estudio. El Ministerio del Interior debe publicar con carácter retroactivo las estadísticas completas de criminalidad, incorporando los datos relativos a las policías autonómicas de Cataluña, Navarra y País Vasco entre 1989 y 2011. El Sistema Estadístico de Criminalidad (SEC) debería mejorar las potencialidades del Portal Estadístico de Criminalidad para facilitar la consulta y descarga de datos desde 1989 a 2011, incorporando más variables de análisis para facilitar una consulta selectiva de tablas según las tipologías que establece el Código Penal vigente.

En lo referente a la realización de Encuestas de Victimización y, pese a que la Criminología reconoce su estratégico valor para el conocimiento e intervención de los fenómenos delictivos, en España su realización ha sido puntual y de escasa periodicidad, a diferencia de otros países como EE. UU., Gran Bretaña o Francia que realizan estos estudios de manera anual o bianual. Y, precisamente porque a los delitos contra la libertad sexual presentan un significativo subregistro de denuncias, el déficit en la realización de EV impide estimar con rigor 
su incidencia e impacto en la población. Por todo ello, el Ministerio del Interior debe impulsar el diseño y ejecución de Encuestas de Victimización rigurosas y de carácter periódico.

Por todo lo dicho, es urgente que el Estado español ejecute los compromisos adquiridos mediante la ratificación del Convenio del Consejo de Europa sobre prevención y lucha contra la violencia contra la mujer y la violencia doméstica (11/V/2011), popularmente conocido como Convenio de Estambul ${ }^{49}$, para acometer sin dilación el diseño de políticas públicas orientadas a sensibilizar, prevenir e intervenir todas las formas que revisten las violencias sexuales. Este compromiso exige recoger datos estadísticos detallados, con periodicidad regular, con el fin de conocer la incidencia real de este suceso, así como sus causas y efectos para garantizar la libertad y seguridad de las víctimas.

\section{REFERENCIAS Y RECURSOS DE INFORMACIÓN}

AEBI, M. y LINDE A. (2010): "El misterioso caso de la desaparición de las estadísticas policiales españolas", Revista Electrónica de Ciencia Penal y Criminología, 12-07, 30 págs.

AEBI, M. y LINDE A. (2010): "Las encuestas de victimización en Europa: Evolución histórica y situación actual", Revista de Derecho Penal y Criminología, núm. 3, pp. 211-298.

ALVIRA, F. y RUBIO, Ma A. (1982): "Victimización e inseguridad: la perspectiva de las encuestas de victimización en España”, REIS, núm. 18, pp. 29-50.

AMNISTÍA INTERNACIONAL (2018): YA ES HORA DE QUE ME CREAS. Un sistema que cuestiona y desprotege a las víctimas, Madrid: AI.

BIDERMAN, A. y REISS, A. (1967): "On Exploring the "Dark Figure" of Crime", Annals of the American Academy of Political and Social Science, 374 (1), pp. 1-15.

BLAY, E. (2013): "El control policial de las protestas en España", InDret, núm. 4, 32 págs.

CARO CABRERA, M. y NAVARRO ARDOY, L. (2017): "La medición del miedo al delito a través de los barómetros del CIS", REIS, núm. 157, pp. 23-44.

CAZORLA GONZÁLEZ, Cristina (2019). "Carencias y desafíos de las estadísticas oficiales para la medición de la violencia sexual en España (2010-2018)", Anuario Internacional de Criminología y Ciencias Forenses, núm. 4, págs. 15-62.

CEDAW (2015): Comité para la Eliminación de la Discriminación contra la Mujer. Observaciones finales sobre los informes periódicos séptimo y octavo combinados de España, CEDAW/C/ESP/Q/7-8, 29 de julio de 2019.

DELEGACIÓN DEL GOBIERNO PARA LA VIOLENCIA DE GÉNERO (2018): Percepción Social de la Violencia Sexual, Madrid, Centro de Publicaciones del Ministerio de Sanidad, Consumo y Bienestar Social.

DÍAZ, J. L. y GARCÍA, E. (Dirs.) (2009): Encuestas a Víctimas en España, Málaga, Instituto Andaluz Interuniversitario de Criminología.

${ }^{49}$ B.O.E. núm. 137, de 6 de junio de 2014, páginas 42946 a 42976. 
DOMENECH, I. y SIRVENT, E. (2017): "Non-partner sexual violence against women in Spain: lifetime prevalence, perpetrators and consequences on mental health", Journal of Public Health, 39 (4), pp. 738-744

EIGE -European Institute for Gender Equality- (2013): The study to identify and map existing data and resources on sexual violence against women in the EU, Luxembourg: Publications Office of the European Union.

FRA - The European Union Agency for Fundamental Rights- (2014): Violence against women: an EU-wide survey. Main results report, Luxembourg: Publications Office of the European Union, disponible en línea file:///C:/Users/Compaq/Downloads/fra2014-vaw-survey-main-results-apr14 en.pdf [consulta: 18-05-2017]

GCE-SES (2018): Informe sobre delitos contra la libertad e indemnidad sexual en España, Madrid: Ministerio del Interior [Gabinete de Coordinación y Estudios de la Secretaría de Estado de Seguridad.

GARCÍA ESPAÑA, E. et al. (2010): "Evolución de la delincuencia en España: análisis longitudinal con encuestas de victimización", Revista Española de Investigación Criminológica, núm. 8, 27 pp.

GONDRA BUSTINZA, Josu (2008): "Los sentimientos de inseguridad y miedo: el origen de una noción", Revista Catalana de Seguretat Pública, abril, pp. 93-104

HCE -Haut Conseil à l'égalité entre les femmes et les hommes - (2016). Rapport final d'évaluation du 4e plan interministériel de prévention et de lutte contre les violences faites aux femmes, disponible en línea http://www.haut-conseil-egalite.gouv.fr/IMG/ pdf/hce rapport violences eval 4e plan 20161122.pdf [consulta: 10-06-2018]

IGAREDA, N. y BODELÓN, E. (2014). "Las violencias sexuales en las universidades: cuando lo que no se denuncia no existe", Revista Española de Investigación Criminológica, 12 (1), pp. 1-27

INE (2014). Política de difusión estadística, disponible en línea http://www.ine.es/ine/ codigobp/politica difusion.pdf [consulta: 15-09-2017]

JIMENO DE TORRES, S. (1980): "El delito de violación y su incremento actual", Anuario de Derecho Penal y Ciencias Penales, Tomo 33, pp. 441-448

MACDOWALL, W.; GIBSON, L.; TANTON, C.; MERCER, C.; LEWIS, R.; CLIFTON, S.; FIELD, N.; DATTA, J.; MITCHELL, K.; SONNENBERG, P.; ERENS, B.; COPAS, A.; PHELPS, A.; PRAH, P.; JOHNSON, A. y WELLINGS, K. (2013): "Lifetime prevalence, associated factors, and circumstances of non-volitional sex in women and men in Britain: findings from the third national survey of sexual attitudes and lifestyles (natsal-3)", Lancet 382, pp.1845-1855

MARÍN, F. (2006): “Análisis estadístico de los delitos contra la libertad e indemnidad sexual", Revista Índice, núm. 17 (marzo)

MURRIÀ, M. (2010): "Las encuestas de seguridad en Cataluña", en 10 años de Encuesta de seguridad pública de Cataluña. Experiencias europeas. Balance y retos de futuro, Barcelona: Generalitat de Cataluña. Departamento de Interior, Relaciones Institucionales y Participación.

NÚÑEZ, J. (2010): Regulación histórica de la agresión sexual y sus objetos de protección. Madrid: Congreso de los Diputados.

DE LEEUW, E.; HOX, J. y DILLMAN, D. (2008): International handbook of survey methodology. London: Routledge Academic.

OSBORNE, R. (2008): “De la «violencia» (de género) a las «cifras de la violencia»: una cuestión política”, EMPIRIA. Revista de Metodología de Ciencias Sociales, núm. 15 , pp. 99-124 
PÉREZ, A. I. y BENITO, D. (2013): "Estudio de los instrumentos existentes para medir la delincuencia", Revista Electrónica de Ciencia Política y Criminología (RECPC), 15-08, pp. 1-34

REGAN, L. y KELLY, L. (2003): "Rape: Still a forgotten issue", Document for the 'Strengthening the linkages - Consolidating the European network project", Child and Woman Abuse Studies Unit, London Metropolitan University, 2003

RODRIGUEZ, V. (2003): Mujeres forzadas: el delito de violación en el derecho castellano (Siglos XVI-XVIII), Almería, Servicio de Publicaciones de la U. de Almería.

SGIP Secretaria General de Instituciones Penitenciarias (2018): Informe General de la Administración Penitenciaria 2017, Valdemoro: Ministerio del Interior. http://www. institucionpenitenciaria.es/web/export/sites/default/datos/descargables/publicaciones/Informe General 2017 acc.pdf [consulta: 09-02-2019]

SEGATO, R. L. (2003): "La estructura del género y el mandato de la violación", Las estructuras elementales de la violencia. Ensayos sobre género entre la antropología, el psicoanálisis y los derechos humanos, Buenos Aires, Universidad de Quilmes.

SERRANO, A. (2011): "Dudosa fiabilidad de las estadísticas policiales sobre criminalidad en España”, Revista de Derecho Penal y Criminología, núm. 6, pp. 425-454

SOLNIT, R. (2016): Los hombres me explican cosas, Madrid, Capitán Swing.

SORTZEN Consultoría (2011): Agresiones sexuales. Cómo se viven, cómo se entienden y cómo se atienden, Vitoria: Servicio Central de Publicaciones del Gobierno Vasco.

SOTO, S. (2005): “La delincuencia en la agenda mediática, REIS, núm. 112, pp. 75-130

TARDÓN, B. (2017): La violencia sexual: desarrollos feministas, mitos y respuestas normativas globales, Tesis doctoral inédita leída en la Universidad Autónoma de Madrid, Facultad de Filosofía y Letras, Instituto Universitario de Estudios de la Mujer -Fecha de lectura: 29-09-2017-, bajo la dirección de Cristina Sánchez.

UN Women, United Nations Entity for Gender Equality and the Empowerment of Women (1995): 'Beijing Declaration and Platform for Action', disponible en http:// www.un.org/womenwatch/daw/beijing/pdf/BDPfA \%20E.pdf [consulta: 13-022017]

van DIJK, J.; van KESTEREN, J. y SMIT, P. (2007): Criminal Victimisation in International Perspective. Key Findings from the 2004-2005 ICVS and EU ICS. 257 Onderzoek en beleid. Den Haag: WODC.

van DIJK, J. y CASTELBAJAC, M. (2015): "The hedgehog and the fox; the history of victimisation surveys from a Trans-Atlantic perspective", en GUZY, Nathalie; BIRKEL, Christoph y MISCHKOWITZ, Robert (Eds.) (2015). Viktimisierungsbefragungen in Deutschland, Wiesbaden: BKA, pp. 10-29, disponible en https:// www.semanticscholar.org/paper/The-hedgehog-and-the-fox\%3B-the-history-ofsurveys-a-Dijk-Guzy/11888b23cf1842281c35abb03ae65aaa4cc96d3a [consulta: 08-06-2017]

VIGARELLO, G. (1999): Historia de la violación: siglos XVI-XX, Madrid: Cátedra.

VON HOFER, H. (2000): "Crime Statistics as Constructs: The Case of Swedish Rape Statistics", European Journal on Criminal Policy and Research, Vol. pp. 77-89 


\section{ANEXO}

Tabla A1: Evolución del total de los delitos denunciados contra la libertad sexual (Hechos conocidos), 1989-2018.

\begin{tabular}{|c|c|c|c|}
\hline Ã̃o & $\begin{array}{c}\text { Denuncias por } \\
\text { delitos contra la } \\
\text { libertad sexual }\end{array}$ & Año & $\begin{array}{c}\text { Denuncias por } \\
\text { delitos contra la } \\
\text { libertad sexual }\end{array}$ \\
\hline 1989 & 5.770 & 2004 & 8.025 \\
\hline 1990 & 5.436 & 2005 & 8.657 \\
\hline 1991 & 5.890 & 2006 & 8.522 \\
\hline 1992 & 5.736 & 2007 & 8.900 \\
\hline 1993 & 6.178 & 2008 & 9.837 \\
\hline 1994 & 6.344 & 2009 & 8.976 \\
\hline 1995 & 6.952 & 2010 & 9.892 \\
\hline 1996 & 6.552 & $2011 *$ & 9.008 \\
\hline 1997 & 6.963 & 2012 & 8.923 \\
\hline 1998 & 7.418 & 2013 & 9.468 \\
\hline 1999 & 7.198 & 2014 & 9.869 \\
\hline 2000 & 6.964 & 2015 & 10.844 \\
\hline 2001 & 6.907 & 2016 & 13.782 \\
\hline 2002 & 7.115 & 2017 & \\
\hline 2003 & 7.234 & & 2018 \\
\hline
\end{tabular}

* incorporación de las estadísticas de Catalunya, Navarra y Euskadi

Fuente: Anuario Estadístico MIR (varios años) 
Tabla A2: Evolución de las denuncias por violación (Hechos conocidos), 1987-2018.

\begin{tabular}{|c|c|c|c|}
\hline Año & $\begin{array}{c}\text { Denuncias por } \\
\text { violación }\end{array}$ & Año & $\begin{array}{c}\text { Denuncias por } \\
\text { violación }\end{array}$ \\
\hline 1987 & 1.755 & 2003 & 1.439 \\
\hline 1988 & 1.729 & 2004 & 1.487 \\
\hline 1989 & 1.724 & 2005 & 1.599 \\
\hline 1990 & 1.790 & 2006 & 1.481 \\
\hline 1991 & 1.936 & 2007 & 1.573 \\
\hline 1992 & 1.599 & 2008 & 1.386 \\
\hline 1993 & 1.563 & 2009 & 1.304 \\
\hline 1994 & 1.603 & 2010 & 1.177 \\
\hline 1995 & 1.723 & $2011 *$ & 1.513 \\
\hline 1996 & 1.139 & 2012 & 1.280 \\
\hline 1997 & 1.094 & 2013 & 1.298 \\
\hline 1998 & 1.281 & 2014 & 1.239 \\
\hline 1999 & 1.126 & 2015 & 1.229 \\
\hline 2000 & 1.265 & 2016 & 1.249 \\
\hline 2001 & 1.257 & 2017 & 1.383 \\
\hline 2002 & 1.402 & 2018 & 1.700 \\
\hline
\end{tabular}

* incorporación de las estadísticas de Catalunya, Navarra y Euskadi

Fuente: Anuario Estadístico MIR (varios años) 
Tabla A3: Distribución mensual de las denuncias por delitos contra la libertad sexual (Hechos conocidos), 1995-2006.

\begin{tabular}{|c|c|c|c|c|c|c|c|}
\hline Fecha & Delitos & Fecha & Delitos & Fecha & Delitos & Fecha & Delitos \\
\hline ene-95 & 474 & ene-98 & 504 & ene-01 & 564 & ene-04 & 561 \\
\hline feb-95 & 466 & feb-98 & 575 & feb-01 & 521 & feb-04 & 592 \\
\hline mar-95 & 517 & mar-98 & 687 & mar-01 & 681 & mar-04 & 665 \\
\hline abr-95 & 508 & abr-98 & 569 & abr-01 & 550 & abr-04 & 599 \\
\hline may-95 & 677 & may-98 & 744 & may-01 & 598 & may-04 & 725 \\
\hline jun-95 & 716 & jun-98 & 750 & jun-01 & 709 & jun-04 & 763 \\
\hline jul-95 & 643 & jul-98 & 714 & jul-01 & 703 & jul-04 & 848 \\
\hline ago-95 & 703 & ago-98 & 738 & ago-01 & 651 & ago-04 & 822 \\
\hline sep-95 & 518 & sep-98 & 754 & sep-01 & 619 & sep-04 & 735 \\
\hline oct-95 & 651 & oct-98 & 634 & oct-01 & 633 & oct-04 & 700 \\
\hline nov-95 & 602 & nov-98 & 625 & nov-01 & 535 & nov-04 & 758 \\
\hline dic-95 & 477 & dic-98 & 461 & dic-01 & 473 & dic-04 & 611 \\
\hline ene-96 & 499 & ene-99 & 474 & ene-02 & 533 & ene-05 & 547 \\
\hline feb-96 & 559 & feb-99 & 465 & feb-02 & 518 & feb-05 & 600 \\
\hline mar-96 & 553 & mar-99 & 633 & mar-02 & 524 & mar-05 & 766 \\
\hline abr-96 & 554 & abr-99 & 624 & abr-02 & 577 & abr-05 & 751 \\
\hline may-96 & 598 & may-99 & 734 & may-02 & 611 & may-05 & 892 \\
\hline jun-96 & 606 & jun-99 & 786 & jun-02 & 693 & jun-05 & 1012 \\
\hline jul-96 & 622 & jul-99 & 743 & jul-02 & 738 & jul-05 & 860 \\
\hline ago-96 & 595 & ago-99 & 779 & ago-02 & 691 & ago-05 & 789 \\
\hline sep-96 & 565 & sep-99 & 650 & sep-02 & 725 & sep-05 & 764 \\
\hline oct-96 & 539 & oct-99 & 646 & oct- 02 & 700 & oct-05 & 740 \\
\hline nov-96 & 436 & nov-99 & 532 & nov-02 & 592 & nov-05 & 661 \\
\hline dic-96 & 426 & dic-99 & 497 & dic-02 & 521 & dic-05 & 629 \\
\hline ene-97 & 417 & ene-00 & 569 & ene-03 & 536 & ene-06 & 579 \\
\hline feb-97 & 487 & feb-00 & 614 & feb-03 & 478 & feb-06 & 613 \\
\hline mar-97 & 581 & mar-00 & 586 & mar-03 & 610 & mar-06 & 704 \\
\hline abr-97 & 597 & abr-00 & 546 & abr-03 & 582 & abr-06 & 650 \\
\hline may-97 & 662 & may-00 & 720 & may-03 & 692 & may-06 & 797 \\
\hline jun-97 & 565 & jun-00 & 677 & jun-03 & 731 & jun-06 & 876 \\
\hline jul-97 & 698 & jul-00 & 676 & jul-03 & 805 & jul-06 & 880 \\
\hline
\end{tabular}




\begin{tabular}{|c|c|c|c|c|c|c|c|}
\hline Fecha & Delitos & Fecha & Delitos & Fecha & Delitos & Fecha & Delitos \\
\hline ago-97 & 706 & ago-00 & 682 & ago-03 & 701 & ago-06 & 816 \\
\hline sep-97 & 639 & sep-00 & 616 & sep-03 & 681 & sep-06 & 734 \\
\hline oct-97 & 602 & oct-00 & 595 & oct-03 & 629 & oct-06 & 716 \\
\hline nov-97 & 448 & nov-00 & 533 & nov-03 & 525 & nov-06 & 620 \\
\hline dic-97 & 470 & dic-00 & 462 & dic-03 & 578 & dic-06 & 537 \\
\hline
\end{tabular}

